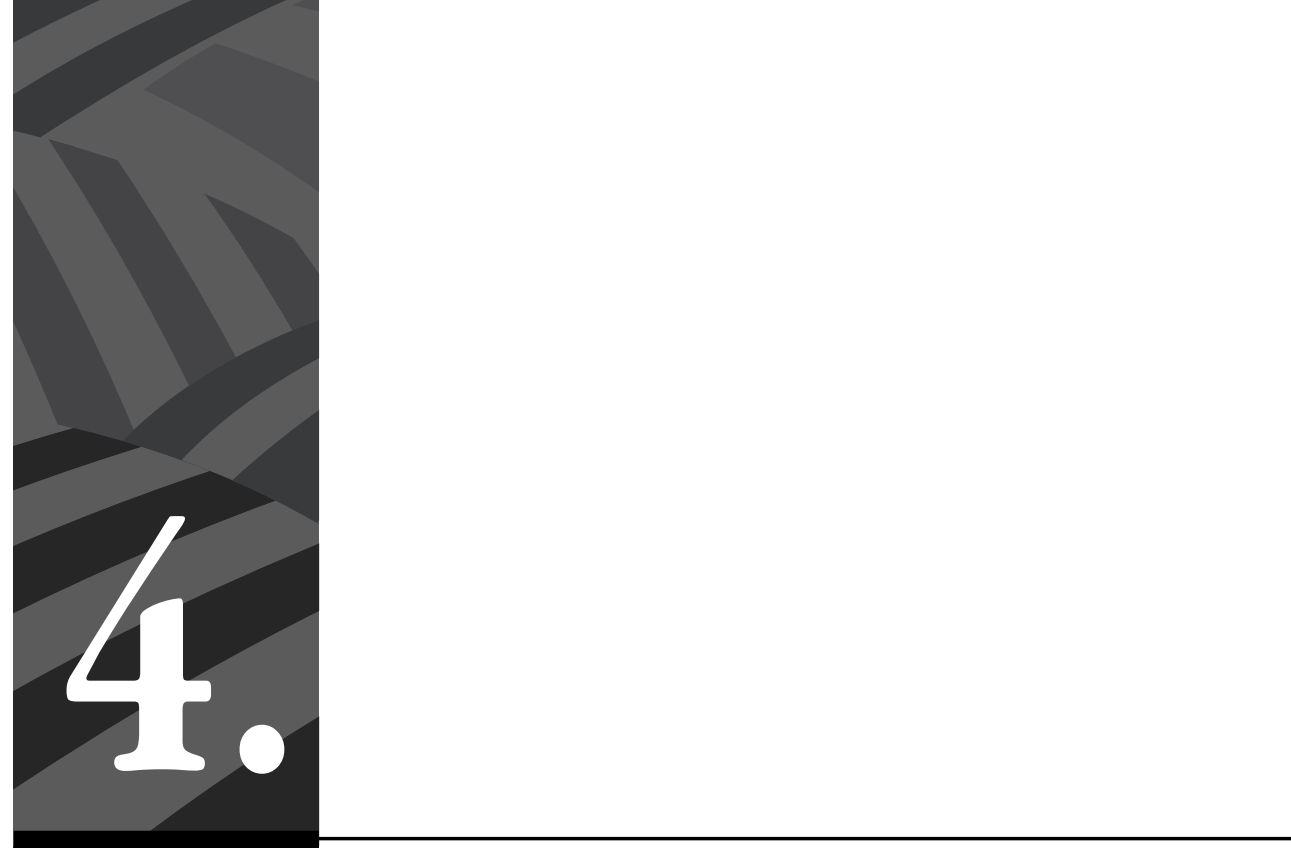

\title{
Análisis sociológico del perdón: discursos dominantes y alternativos
}




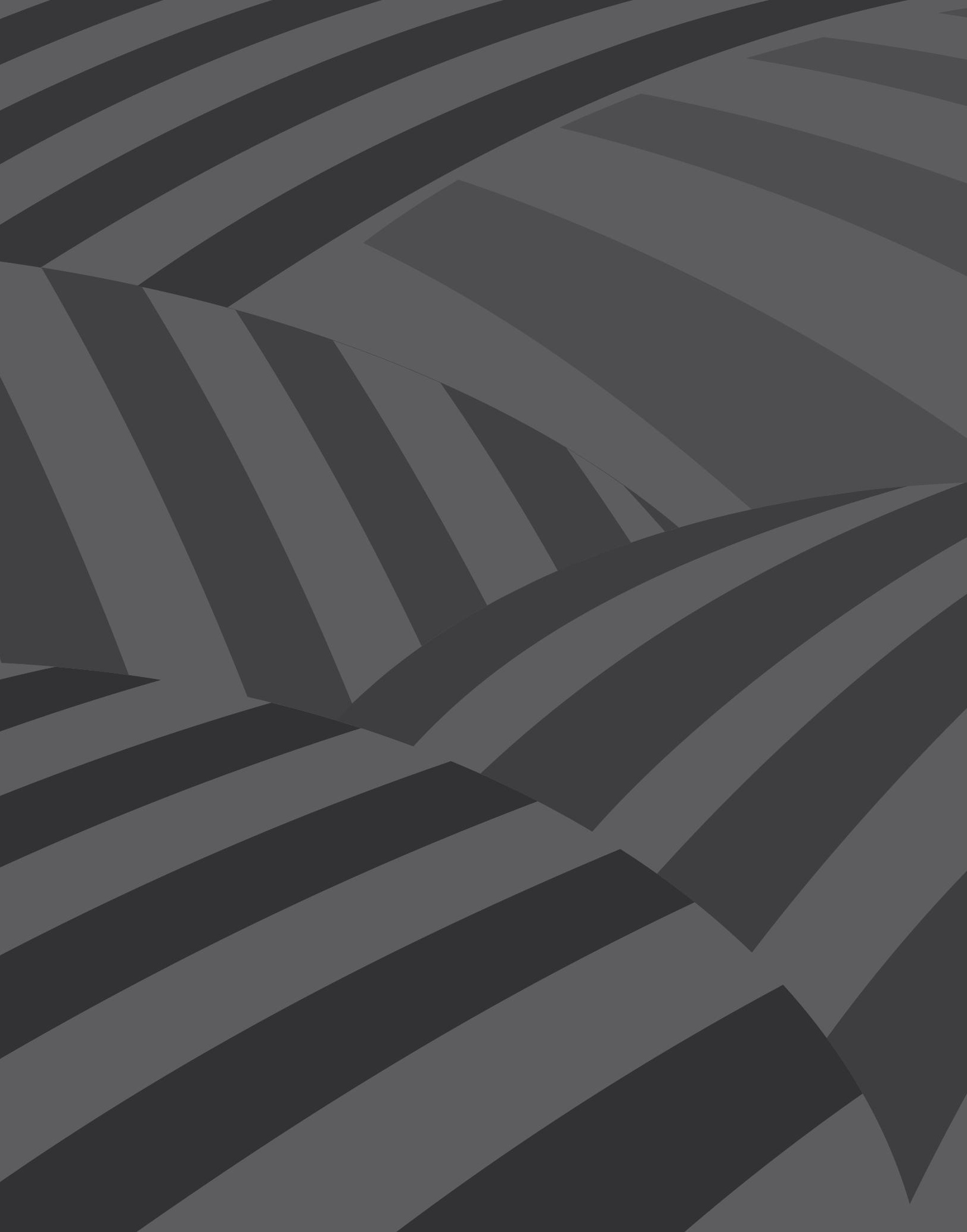




\section{Análisis sociológico del perdón: discursos dominantes y alternativos}

\section{Por Laura Henao**}

Resumen: ¿Qué significa el perdón? ¿Está el perdón en el centro de las narrativas de los sobrevivientes del conflicto? ¿Qué tan cerca se encuentran las narrativas de la prensa de las narrativas propias de quienes sufrieron el conflicto armado colombiano? La comparación de los discursos de los medios de comunicación con testimonios de víctimas, sugiere que existe una brecha en las narrativas de ambos al referirse a mecanismos de reparación. El perdón no está en el centro de las narrativas de las comunidades. En ese panorama, se hace necesario un estudio que muestre hasta dónde la narrativa del perdón ha sido institucionalizada para la reconfiguración del país, alejándose de las concepciones propias de quienes sufrieron violencia. Esto es de especial importancia en regímenes de transición.

La metodología de la presente investigación recoge métodos mixtos novedosos que permiten acercarse al objeto de estudio: el perdón como narrativa de reconciliación. El uso de métodos cualitativos como el análisis de textos, y de métodos cuantitativos como Topic Modeling, hacen del presente estudio una investigación novedosa. Para ello, se analizaron 1.407 artículos de prensa de los dos principales diarios del país (El Tiempo y El Espectador) y de la revista con mayor circulación (Semana), y se compararon con 407 relatos y testimonios de víctimas de cinco casos emblemáticos, entendiendo los primeros como discursos dominantes, y los segundos como discursos alternativos.

Palabras clave: narrativas, perdón, Topic Modeling, amnistías, indultos, opinión pública.

\section{Sociological analysis of forgiveness: Dominant and alternative discourses}

Abstract: What does forgiveness mean? Is forgiveness at the center of the narratives of conflict survivors? How close are the narratives of the press to the narratives of those who suffered the Colombian

* El presente artículo toma y actualiza los apartados, planteamientos e ideas del trabajo de grado para optar por el título de Magíster en Sociología de la Universidad Nacional de Colombia, titulado "Análisis sociológico del perdon: discursos hegemónicos y contra-hegemónicos”. Una versión completa de dicho documento se puede consultar en: http://bdigital.unal.edu.co/51988/1/1020742390.2016.pdf

** Economista, Magíster en Economía y Magíster en Sociología, especialista en Derechos Humanos y Derecho Internacional Humanitario. Actualmente, es investigadora del Cinep/PPP. 
armed conflict? The comparison of the speeches of the media with testimonies of victims suggests that there is a gap between both narratives when referring to mechanisms of reparation. Forgiveness is not at the core of the narratives of the communities. In this scenario, a study is necessary to show how far the narrative of forgiveness has been institutionalized for the reconfiguration of the country, moving away from the conceptions of those who suffered violence. This is especially important in transition regimes. The methodology of this research includes novel mixed methods that allow us to approach the object of study: forgiveness as a narrative of reconciliation. The use of qualitative methods such as text analysis, and quantitative methods such as Topic Modeling, make this study a novel investigation. To this end, 1,407 press articles were analyzed from the country's two main newspapers (El Tiempo and El Espectador) and from the magazine with the largest circulation (Semana), and were compared with 407 stories and testimonies from victims of five emblematic cases, understanding the former as dominant discourses, and the latter as alternative discourses.

Keywords: narratives, pardon, Topic Modeling, amnesties, pardons, public opinion.

Cómo citar este artículo: Henao, Laura (2017). Análisis sociológico del perdón: discursos dominantes y alternativos. Revista Controversia, 209, 111-168.

Fecha de recepción: 21 de julio del 2017

Fecha de aprobación: 19 de noviembre del 2017

Después de más o menos dos años... creí que debía elegir entre perdonar para poder seguir adelante o no perdonar y seguir aferrada a la rabia y al sufrimiento [...]. Hay muchos que creen que el perdón es condición necesaria para la reconciliación. Eso no es cierto en mi caso. (Wendy Lanski, 2015, sobreviviente del ataque del 11 de septiembre de 2001).

\section{Introducción. Del perdón y otras narrativas}

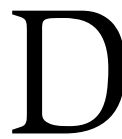

iariamente, los medios de comunicación lanzan mensajes sobre la guerra, que coexisten con noticias sobre perdón. Los noticieros y los periódicos narran el conflicto colombiano, pero descuidan las narrativas de reconciliación. ¿Qué pasa con los testimonios y las iniciativas de quienes sufrieron la guerra, que hoy recuerdan más la superación del trauma que el perdón?

La presente investigación busca explorar la dinámica del perdón en el contexto colombiano, caracterizado por una guerra prolongada. A su 
vez, busca mostrar la lucha discursiva entre las narrativas en los medios de comunicación y los referentes de las víctimas para superar los hechos violentos, dificultando la extensión de la solidaridad con los sobrevivientes del conflicto. Las representaciones que surgen de las narrativas de los medios de comunicación y de las propias víctimas deberían lograr una dinámica de reconciliación que anime a la sociedad civil para dar lugar al posconflicto.

El perdón ha tenido múltiples usos en las ciencias sociales. Desde la filosofía se ha discutido sobre sus usos reparadores y sobre su relación con el olvido. Algunos filósofos (Acosta, 2011 y Arendt, 2005)) plantean que el perdón funciona como mecanismo de recuperación de los tejidos rotos por la violencia y es necesario para disminuir las consecuencias incalculables de la acción. Es un mecanismo mediante el cual se puede disminuir la carga de la ofensa (Ricoeur, 2003; Derrida, 2008). Desde la teología, los perdones son vistos como actos fundacionales, como cuando Esaú perdona a Jacob y ambos realizan "un acto fundacional de la genealogía de Israel” (Valcárcel, 2010, p.46). Desde la ciencia política son entendidos como un proceso "micropolítico de aprendizaje" para resolver el problema de la convivencia en escenarios de violencia (Garrido, 2008, p.123). Desde la esfera político-jurídica, el perdón juega un papel importante en la justicia transicional dependiendo de la dosis que se aplique: "perdones responsabilizantes, compensadores, recíprocos y amnésicos” (Uprimny, 2006, p.23). Desde la sociología, se relaciona con el individuo y con la colectividad: con el individuo, pues es un "acontecimiento" que se encuentra en el marco de una "relación personal con alguien” (Jankélévitch, 1967); por el lado de la colectividad, está asociado a la memoria y es usado como "un reconocimiento público de los eventos experimentados por la colectividad” (Garrido, 2008, p.147).

Desde la sociología, aunque algunos (Boltanski, 2000; Boltanski y Thévenot, 1987) se han propuesto devolverle "la realidad sociológica" al perdón y compararlo con un hecho social por ser una forma de interacción social, para otros (Lefranc, 2006, pp.196-202) este parece 
imposible, en el marco de esas relaciones, por carecer de un principio de reciprocidad (es un don gratuito).

En ese panorama, se hace necesario un estudio que muestre hasta dónde la narrativa del perdón ha sido utilizada de manera dominante por funcionarios públicos y por medios de comunicación, alejándose de las concepciones propias de quienes sufrieron violencia. Esto es de especial importancia en regímenes de transición en los que las élites median fuertemente el proceso para pasar de un estado político a otro (Edles, 1998). Los valores culturales que se inscriben en los procesos de transición no son siempre homogéneos y es la lucha entre ellos lo que dificulta el paso expedito hacia un nuevo régimen. En ese sentido, la presente investigación busca mostrar las diferencias culturales en dos narrativas sobre reconciliación que parecen montadas en discursos diferenciados: por un lado, los medios de comunicación, y por el otro, los testimonios de los sobrevivientes del conflicto colombiano.

En el primer acápite se ofrece el marco teórico sobre el cual se establece la discusión entre las diferentes concepciones sobre el perdón. Pasando por perspectivas filosóficas, teológicas, político-jurídicas y sociológicas, se discute el papel del perdón y su relación jurídica con las amnistías en distintos contextos que han tenido transiciones de regímenes dictatoriales hacia regímenes democráticos, o de conflictos armados hacia la paz. Por ejemplo, Colombia, en su búsqueda por la paz, ha utilizado amnistías como herramienta de reconfiguración de un orden social en guerra permanente. Estos aportes permitirán conocer los alcances del perdón y su institucionalización (Minow, 1998; Minow et al., 2011) como categoría jurídica para la reconciliación en los regímenes de transición.

En consonancia con lo anterior, el acápite dos, "Breve historia del perdón jurídico en Colombia”, tiene como objetivo contextualizar el debate sobre la institucionalización del perdón en nuestro país. De esta forma, se entenderá cómo el perdón ha sido un referente importante para la reconfiguración del país y cómo las amnistías se han utilizado para alcanzar 
un nuevo orden social. Así, en Colombia, los discursos de perdón han convivido con acciones de guerra y no se ha logrado encontrar solución a las causas estructurales del conflicto (Molano, 1980; Sánchez, 1985; Villar Borda, 1982; Uribe, 2003).

El acápite tres introduce la metodología de la investigación y da cuenta de la importancia de nuevos métodos para el análisis de narrativas. Entre ellos se contemplan aquellos usados para analizar grades cantidades de información, en una era en la cual el Internet ha facilitado la adquisición de textos. Nuevas herramientas como topic modeling han facilitado la clasificación de la información. No obstante, como cualquier metodología, esta tiene fortalezas y limitaciones que serán evidenciadas en esta sección para extender el debate sobre su uso en las ciencias sociales. De la mano de lo anterior, en este acápite se pretende analizar la opinión pública desde el 2008, año en el que el porcentaje de noticias que hacen referencia al perdón aumenta en el discurso público colombiano. Lo que se observa es una mezcla de temas alrededor del perdón que se usan para ambientar a la sociedad sobre decisiones trascendentales. El análisis se centra en los dos diarios más importantes del país, El Tiempo y El Espectador, y en la revista Semana, es decir, los de mayor alcance en Colombia tanto por tiraje como por ventas. De ellos se analizarán editoriales, columnas de opinión, crónicas, reportajes, entre el 2008 y el 2015, para mostrar un espectro amplio de lo que ambos diarios publican. El referente central de la búsqueda es el perdón como mecanismo de reconciliación.

Las narrativas de prensa contrastan con aquellos referentes utilizados por los sobrevivientes para hablar de lo que pasó y muestran una fragmentación entre las agendas periodísticas y los referentes primarios de las comunidades que sufrieron directamente el conflicto colombiano. De esto da cuenta el acápite cuatro, "Casos emblemáticos: ¿cuáles son las narrativas de los sobrevivientes?”. El acápite cinco presenta las conclusiones obtenidas. 


\section{Teorizar sobre perdón y trauma}

En países que atraviesan procesos de transición de la violencia a la paz o de la dictadura a la democracia, una variable que juega un papel preponderante en los discursos políticos, morales, jurídicos, históricos y sociales para la reconstrucción es el perdón como figura de reconciliación. El perdón es una figura con múltiples aristas y puede abarcarse desde distintas esferas. A continuación, algunas voces del debate.

\subsection{Concepciones sobre el perdón}

Dentro de la filosofía, algunos autores han tratado el perdón como una figura para restablecer los lazos rotos en una comunidad, después de haber sufrido violencia, especialmente por los efectos reparadores de aquel, ya sea para los individuos, ya para la comunidad. La definición del perdón es compleja. Según Derrida (2008), es una figura que por naturaleza no es pura y es contradictoria: el perdón solo puede “perdonar lo imperdonable”. La pureza también radica en que el perdón no tiene un objetivo específico:

Siempre que el perdón está al servicio de una meta, por noble o espiritual que esta sea (indulto o redención, reconciliación, salvación) [...] entonces el "perdón" no es puro —ni lo es su concepto. El perdón no es, no debería ser, ni normal, ni normativo, ni normalizante [...] El perdón perdona solo lo imperdonable (p.117).

El perdón parece ser una reconciliación más íntima e individual, perteneciente al plano privado, y no una perteneciente al ámbito de lo político - amnistías, indultos, derecho de gracia- (Derrida, 2008; Ricœur, 2003). Es una acción mediante la cual el individuo es capaz de reconciliarse con la realidad y una experiencia en la que el sujeto "decide afrontar el presente de otro modo, interrumpiendo el curso del tiempo y de las heridas que carga consigo" (Acosta, 2011). El perdón es, entonces, el movimiento que permite darle continuidad a los lazos rotos de 
las relaciones primarias y una acción capaz de disminuir la profundidad de la falta ejercida por el ofensor (Ricœur, 2003). Incluso, puede ser un acto capaz de generar mayores niveles de bienestar y felicidad (Enright y North, 1998).

En ese sentido, cuando existen contextos límites en donde se pone a prueba la "analogicidad del ser”, es decir, cuando se acepta que en los seres humanos conviven tanto el bien como el mal, la humanidad es capaz de ver la acción fuera del individuo: "vales más que tus actos" (Ricoeur, 2003, p.643). En este orden de ideas, la figura del perdón puede ser definida como el mecanismo mediante el cual un individuo es capaz de aceptar la irreversibilidad de una acción y, por lo tanto, concederle a otro individuo la tranquilidad de haber superado el mal que causó la acción indeseable. El perdón funcionaría para deshacer los actos del pasado y para recobrar una fuerza que fue perdida con una acción "monstruosa”. Si no existiese esta figura, la capacidad de actuar del ser humano quedaría “confinada a un solo acto” del que seríamos víctimas por siempre (Arendt, 2005, p.256): “La posible redención del predicamento de irreversibilidad — de ser incapaz de deshacer lo hecho, aunque no se supiera, ni pudiera saberse, lo que se estaba haciendoes la facultad de perdonar”.

Gracias al perdón, las personas se pueden reinsertar en la pluralidad y continuar con su vida, reconciliándose con una "realidad histórica concreta" que fue rota o destruida (Acosta, 2011). De esta manera, vamos moviéndonos hacia un perdón con efectos en la esfera pública, ya que este depende de la presencia de los otros para su realización. Sin ellos, carece de realidad (Arendt, 2005). En esta esfera pública, el perdón, asociado a la incapacidad de castigar lo que ha resultado imperdonable (p.260), puede ser un recurso de los actores para reafirmar una responsabilidad moral que no fue obtenida a través de la culpabilidad jurídica:

Al introducir la responsabilidad moral, la figura del perdón responde, quizás, a la necesidad de una incriminación de los individuos ya no permitida por la culpabilidad jurídica, y traduce la dificultad de una determinación 
del componente institucional de la culpa: la invocación del perdón se inscribiría entonces en una tentativa de reformulación de un principio adecuado de responsabilidad política (p.207).

Con el perdón no se borraría la culpa, sino que se evidenciaría. Los individuos perdonan a quien es culpable, porque al ser considerado como tal, ya sea por declaración propia, ya sea por un señalamiento hecho por parte de las víctimas, en él recae la responsabilidad de los actos. Además de ello, el perdón renueva la relación entre los ofendidos y los ofensores, quienes ya no se aferran a sus antiguos roles, sino que renuevan su relación (Lefranc, 2005). El perdón, en esos casos, trata de mediar entre la estabilidad que se quiere en un nuevo sistema democrático y la justicia que se quiere aplicar a los responsables de delitos cometidos durante un régimen autoritario previo a la democracia, funcionando como un procedimiento de expiación que permite a los ofensores reintegrarse en la sociedad (Melo, 2002, p.176).

El perdón también puede ser visto como un "tipo de novedad normativa” relacionada con la memoria, con los “recuerdos en común”, lo que conforma la identidad. Los saberes y normas, el lenguaje y las técnicas, el arte y los ritos. “Un Per-don, un supra don” (Valcárcel, 2010, p.12). Pero ¿qué pasa allí donde el acervo se perdió y la identidad común quedó dispersa en un territorio desgastado? ¿Acaso no implica un peso para quien otorga el perdón?

El perdón también tiene relación con la memoria. A pesar de lo que sugiere Boltanski (2000), no implica una voluntad de olvidar, implica recordar, emoción directamente conectada con la memoria: "El perdón no es olvido [...]. Para perdonar es preciso recordar” (Jankélévitch, 1967; Lefranc, 2005, p.174). Pero ¿qué sucede cuando las relaciones cotidianas son la principal forma de entender la comunidad? Es decir, ¿qué pasa cuando la confianza se pierde, cuando el tejido social es difícil de reconstruir y el perdón no es acogido por la comunidad? ¿No habría que apelar a un momento previo al perdón? 
La idea del perdón no parece tan antigua. Incluso Jankélévitch (1967) asegura que el mundo antiguo no conoció el perdón. En el Antiguo Testamento se observa que Yahvé castiga con pestes al pueblo hebreo, independientemente de quien haya cometido la falta: "Al mal ha de seguirse con otro mal, conmutativo con el primero, que restaure la justicia. Un nuevo mal, incluso estrictamente conmutativo" (Valcárcel, 2010, p.37). De igual forma, en el objetivismo moral, la idea de que el arrepentimiento conmuta el daño es inconcebible. El daño está ahí y busca satisfacción (pp.30-33). No obstante, muchas veces el perdón es usado como narrativa de los gobiernos, en medio de un cálculo estratégico y político (Derrida, 2008, p.123).

\subsection{El perdón en los regímenes de transición}

En las transiciones de un régimen a otro, algunas narrativas de reconciliación transmiten un mensaje que apela a la identidad nacional y a los lazos de solidaridad que están desgastados por la guerra. Un ejemplo clásico es Sudáfrica. En ese país, la Comisión de Verdad y Reconciliación abrió un espacio para la creación de una nueva identidad nacional, una que reposaba en el reconocimiento de lazos de solidaridad. El éxito del performance de reconciliación radicó no solo en que ofreció una catarsis, sino también un camino hacia nuevas definiciones de pertenencia (Goodman, 2006). Sin embargo, si el lazo de solidaridad al que apela la narrativa falla, los nuevos sistemas tendrán olas de crímenes iguales o peores que los anteriores. En Sudáfrica sucedió. Los crímenes aumentaron en 1995 debido a la débil inclusión de grupos dentro de una verdadera identidad nacional (Brogden, 1999).

En el contexto sudafricano, la narrativa del perdón fue acogida ${ }^{1}$, hasta por los más reacios, “a condición de que ese perdón surgiera de la sociedad civil”, como un acto colectivo, "que sirviera de pretexto para

1 Aunque de las 7700 personas que solicitaron amnistía solo fue concedida en 1200 casos (Hamber, 2003, p.1078, citado por Uprimny, 2006, p.31). 
escuchar la voz de los muertos, de los desplazados, de los desaparecidos, de los secuestrados, de las viudas y los huérfanos" (Chaparro, 2005, p.234). En el caso africano, “únicamente si el perdón ocupaba un lugar central sería posible una salida pacífica del régimen del apartheid” (Rivas y Marrodán, 2007) y, por lo tanto, se podría explorar una nueva vida. En Sudáfrica,

los antiguos criminales tuvieron que participar en la reescritura de la historia nacional para ser perdonados: la inmunidad se merece, implica el reconocimiento público de sus crímenes y la aceptación de las nuevas reglas democráticas [...]. En el extremo sur del continente africano [...] un país exploró una nueva vida, la del perdón para quienes reconocen sus ofensas (Ricœur, 2003, p.618).

La falta efectiva de castigos en Sudáfrica y un verdadero arrepentimiento tuvieron consecuencias funestas: "Confesar para no terminar ante los tribunales [...] No responder a las preguntas de la víctima, sino cumplir con los criterios legales de los que depende la amnistía” (Ricœur, 2003, p.629). Según Wilson (2002), dado que la exigencia de castigo fue sacrificada por la verdad y los derechos humanos fueron reducidos a la exigencia política y la reconstrucción de nación, el proceso transicional sudafricano tuvo como consecuencia un aumento en el índice de criminalidad desde la transición (Uprimny, 2006, p.131). De acuerdo con Crocker (2002), el efecto disuasivo del castigo se debilita cuando la gente cree que puede romper la ley y salirse con la suya.

Cuando los procesos de perdón son instaurados por los Estados como políticas de reconciliación, ¿no puede significar una carga para las víctimas? Cuando el perdón "surge de una situación de indefensión prolongada” se puede convertir en "un acto que refrenda el daño" y mantiene un estado de impunidad (Chaparro, 2005, p.242). Sin embargo, según este autor, cuando el perdón es la consecuencia de una verdadera acción colectiva, "un perdón sin soberanía”, que no espera nada a cambio, puede otorgar "un sentido nuevo a la acción de la comunidad de 
sobrevivientes del conflicto y se convierte en una práctica política y vital de los ciudadanos en su conjunto” (p.255). No obstante, este perdón debe estar acompañado de una actitud social y de una capacidad de la sociedad para efectivamente avanzar hacia el mismo, para demandar justicia y reparación y equilibrar la correlación de poderes existente en la sociedad (Vargas, 2002).

En el proceso de transición de Chile, durante su fase inicial, se dieron amnistías generales acompañadas de otras instituciones en favor de la verdad y la reparación a las víctimas, generando lo que Uprimny (2006) denomina perdones compensadores. Sin embargo, este tipo de amnistías generó una visión de impunidad para los responsables, como sucede muchas veces cuando el perdón ocupa un rol protagónico dentro de la transición. Años después, los chilenos seguían apoyando un castigo para los criminales y concebían que enjuiciar a los culpables, especialmente a Pinochet "ayudaría a unificar la nación, así como a consolidar la democracia en Chile” (Crocker, 2002, p.216). El juicio de Pinochet fue un símbolo de justicia que desencadenó esperanzas sobre la captura de antiguos criminales (Roht-Arriaza, 2005) y demostró que subestimar el poder reconciliador de la justicia es igual de peligroso que "sobreestimar los efectos restaurativos de la amnistía y el perdón” (Crocker, 2002, p.216).

Para el caso argentino, en una primera etapa el perdón ocupó un papel secundario para dar paso a la justicia. En ese país hubo una serie de hitos jurídicos, empezando por el juicio a las Juntas que en 1985 condenó a los principales participantes de la Dictadura (1976-1983) (Hilb, 2012, p.131). El capitán Antonio Scilingo “describió de manera detallada su participación en los vuelos de la muerte, donde desde aviones de la Armada prisioneros vivos eran arrojados al mar” (p.143). El resultado fue su detención en España y una condena a 640 años de prisión por crímenes de lesa humanidad. "Desde entonces ningún perpetrador tuvo la ocurrencia de hablar” (p.143). Sin embargo, estos hitos fueron frenados desde muy temprano por las Leyes de Punto Final y Obediencia Debida, y por la Ley de Amnistía de 1990, que mantuvieron muchos años la impunidad en 
Argentina, solo gradualmente disminuida con la nulidad de estas en 2004 (Hilb, 2012; Uprimny, 2006; Lefranc, 2005).

En Perú, en el proceso de restablecimiento de los vínculos deteriorados por el conflicto², el perdón fue entendido como "una gracia otorgada por la víctima de un daño a su perpetrador, en el sentido de otorgarle un don” (Comisión de la Verdad y la Reconciliación de Perú, 2003, p.24). Fue concebido como un bien superlativo y como un acto perteneciente a la libertad del individuo. Perdonar suponía "superar la venganza y afirmar en actitud positiva la vida y el futuro” (p.24). Sin embargo, fue gracias al valor cultural de la reciprocidad en el campo que los arrepentidos pudieron trabajar con la comunidad y a favor de esta. "Fue una manera de rehabilitar a los exenemigos y de convertirlos en runa masinchik, gente como nosotros, gente con la que trabajamos" (Theidon, 2004).

Respecto al castigo impartido a los criminales, el relator especial de las Naciones Unidas sobre ejecuciones sumarias, en su informe de visita al Perú en 1996, declaraba que "la institucionalización de la impunidad" en este país es uno de los principales problemas en relación con la falta de respeto por el derecho a la vida (Amnistía Internacional, 1996). Lo anterior, haciendo referencia a la aprobación de la Ley 26.479 del 14 de junio de 1995, la cual otorgó amnistía general “a todos aquellos miembros de las fuerzas de seguridad y a todos aquellos civiles que se encontrasen denunciados, investigados, encausados, procesados o condenados por violaciones de derechos humanos cometidas entre mayo de 1980 y el 15 de junio de 1995” (Amnistía Internacional, 1996). Sin embargo, como lo manifestó Francisco Tudela, Ministro de Relaciones Exteriores del Perú en ese momento, la Ley de Amnistía hacía parte de un proceso de pacificación para superar el conflicto. Con lo cual vemos que se trata de la misma preocupación: “conseguir que la nación

2 En Perú se dio una enorme discriminación, especialmente hacia las comunidades indígenas, que dejó, entre 1980 y el 2000, un saldo estimado de 69280 personas víctimas del conflicto (CVR, Anexos, 2003, p.17). 
sobreviva a sus discordias, que los traumas vayan desapareciendo con el trabajo de duelo y que el Estado-Nación no se vea embargado por la parálisis” (Derrida, 2008, p.125).

En Guatemala, el presidente de la República, el 29 de diciembre de 1998, aclaraba que era consciente de que el perdón "es un acto simbólico, y que ni él ni nada pueden reparar lo que pasó, porque ya nada puede cambiar lo ocurrido”. (Discurso del presidente Arzú Irigoyen, 16 de marzo 1999, citado en Chirouze Montenegro, 2010, p.1394). El perdón es aún más difícil dado que una de las políticas utilizadas por el Estado durante el conflicto interno en este país consistió en desestructurar los valores culturales que aseguraban una cohesión y una acción colectiva de las comunidades. La zozobra producida por la no identidad nacional se vio magnificada por el terror que perduró mucho después del descenso de los niveles de violencia, ya que aquel no se redujo a los hechos violentos ni a las operaciones militares, sino que dependió de mecanismos conexos como "la impunidad de los ejecutores, las extensas campañas para criminalizar a las víctimas y la implicación forzada de la población civil en la cadena causal y la ejecución efectiva de las atrocidades" (Comisión para el Esclarecimiento Histórico, 1999, párrafo 47). Por ello, la reconciliación se dificultó al eliminar gran parte del acervo cultural que mantenía unidos los lazos de comunidad y los contenidos simbólicos e identitarios. La reconstrucción de estos no tiene siempre al perdón como un pilar fundamental ya que, para las víctimas, a veces "la confrontación diaria con sus victimarios mantiene viva la memoria dolorosa de las violaciones” (Comisión para el Esclarecimiento Histórico, 1999, párrafo 52).

El castigo tampoco fue protagonista en Guatemala. El presidente Efraín Ríos Montt, a quien algunos exguerrilleros guatemaltecos como Julio César Monte le atribuyen la responsabilidad de la muerte de setenta mil 
personas en un solo año, de las doscientas mil que dejó el conflicto de 36 años, aún no le ha cumplido a la justicia (López de la Roche, 2002, p.227)³.

El perdón ha ocupado diferentes papeles en los procesos de Justicia Transicional. Según Uprimny (2006), en función de su contenido, los procesos de Justicia Transicional se pueden dividir en cuatro tipos: Perdones amnésicos como sucedió en España ${ }^{4}$, en donde no se contemplaron estrategias para el esclarecimiento de la verdad, con el fin de facilitar las negociaciones y alcanzar la reconciliación nacional, pero a través del olvido total (p.23). Perdones compensadores como en Chile, en donde hubo amnistías generales pero acompañadas de comisiones de la verdad. Perdones responsabilizantes como en Sudáfrica, en donde se buscó un equilibrio entre las exigencias de justicia y de perdón, individualizando responsabilidades. Y transiciones punitivas como en Núremberg, Yugoslavia y Ruanda, en donde se establecieron tribunales ad hoc para castigar a los responsables de crímenes de lesa humanidad y así poder erigir un orden democrático nuevo (p.23).

Asimismo, el perdón ha tenido diferentes papeles en las transiciones. Promotores de la democracia, defensores de antiguos regímenes, el Estado, las víctimas y los victimarios, todos se han expresado frente a las propuestas de perdón: “¡Ni olvido ni perdón!”, dicen las Madres de la Plaza de Mayo en Argentina (Lefranc, 2005, p.21). “¡Ni perdón, ni olvido!”; "Por la vida y la dignidad de los pueblos. Ni perdón, ni olvido” son arengas lanzadas por miembros de la comunidad de El Naya en una conmemoración hecha en su comunidad para recordar la masacre que sufrieron en el 2001 por parte de paramilitares en Colombia (Jimeno et al.,

3 En 2013, Ríos Montt fue condenado a ochenta años de prisión por violación de derechos humanos y genocidio, sentencia que fue revocada el mismo año, por lo cual el exdictador sigue sin pagar por los crímenes cometidos contra el pueblo maya ixil entre 1982 y 1983 (BBC Mundo, 2015).

4 En España hubo un total olvido e impunidad de los hechos de la Guerra Civil y del franquismo (Melo, 2002). La Ley de Amnistía de 1977, tras la muerte de Franco, exoneró los crímenes cometidos antes del 15 de junio de 1977 (Agencia Estatal Boletín Oficial del Estado, Gobierno de España, 2015). 
2009). “Ah, ah... eso nunca se olvida, uno quiere que hagan justicia, pero mientras eso, necesita encontrarlos... No sé si perdoné o vaya a perdonar, pero necesitaba saber”. (Notas de campo Memoria Histórica, Conversación con mujer madre de joven desaparecida, febrero del 2011, Centro Nacional de Memoria Histórica, 2011, p.332).

El perdón es una figura asociada a la justicia restaurativa. Para esta última, "la reconciliación implica necesariamente que todos los actores, víctimas y victimarios, estén absolutamente de acuerdo con la necesidad de perdonar” (Uprimny y Saffon, 2006, p.126). Esto puede ser contraproducente porque si una transición busca la democracia no puede exigir a las víctimas un perdón y vínculos estrechos con sus agresores. Ello implica "excluir, marginar y deslegitimar el punto de vista de muchos” (p.126). Dada las características del conflicto colombiano - como la victimización múltiple de la sociedad civil (Uprimny y Saffon, 2006) - , un perdón absoluto es difícil, especialmente, cuando los derechos humanos de las víctimas siguen siendo violados.

\section{3 ¿Narrar para perdonar?}

Los seres humanos están capacitados para hacer interpretaciones del mundo que los rodea y para crear significados a partir de sus experiencias cotidianas. Estas interpretaciones pueden tener un carácter funcional, pero también están determinadas por profundos lazos afectivos y de identificación personal entre los individuos (Alexander et al., 2006). Los actores pueden compartir el significado de su situación social evidenciando sus orientaciones culturales, los valores a los que le conceden mayor valor y los usos deliberados de sus símbolos. Mediante esta capacidad humana, los actores transmiten sentimientos de cohesión a una comunidad, revelan el sentido de sus vidas o relatan cómo fue roto su mundo. Es así como los actores pueden describir actos de violencia de los que fueron víctimas y la forma en que los vivieron y superaron. 
En contextos donde la violencia rompió el tejido social, la sociedad puede apelar a narrativas para contar lo sucedido. Cuando estas son utilizadas por la colectividad, los traumas culturales pueden emerger. Un proceso de trauma cultural ocurre cuando los miembros de la colectividad sienten que vivieron una experiencia horrenda que dejó "marcas indelebles en la consciencia colectiva, marcando su memoria para siempre y cambiando su identidad futura irrevocablemente" (Alexander et al., 2004, p.1). Al identificar la causa del trauma, los miembros de la colectividad apelan a la solidaridad de otros (p.1). Esto ocurrió con el caso de la construcción de la narrativa del holocausto judío (Alexander y Dromi, 2011, pp.107-132), cuya configuración fue entendida por las comunidades occidentales no judías como el incidente más brutal y significativo del siglo Xx. Es a partir de la construcción de traumas culturales que las sociedades no solo identifican cognitivamente la existencia del sufrimiento humano, sino que adquieren la responsabilidad por él.

Para comprender y explicar lo vivido, las sociedades apelan a diferentes recursos culturales (Alexander y Smith, 1993). Cuando las personas están contando la historia de sus vidas pueden hacer uso de estos recursos apelando al bien o al mal, categorizando quiénes son sus amigos y sus enemigos, señalando a los culpables de la ruptura de sus tejidos y proponiendo el tipo de castigo que merecen quienes lo hicieron. De esta manera, pueden dividir el mundo en esencias que separan lo puro (su comunidad) de lo impuro (quien la profanó) y crean una red de conocimientos que legitiman historias, crean leyes y generan efectos poderosos de transformación. Gibson (1994), por ejemplo, mostró cómo la cultura del guerrero, luego de la derrota en la Guerra de Vietnam, afectó la vida cotidiana en todos los niveles en Estados Unidos. Los relatos de honor y de gloria, principios fundamentales en la mitología guerrera años después del fracaso en Vietnam, ayudaron a fortalecer la visión de Vietnam como un símbolo del mal, así como a combatir la representación de la cobardía, la corrupción política, el deterioro de la economía y las mujeres revoltosas. Estos elementos nutrieron el patriotismo americano, alimentando una narrativa de sacrificio, sangre y violencia (Marvin e Ingle, 1999). 
Según la sociología cultural, para que la narrativa que cuentan las víctimas genere mayor solidaridad debe apelar a un sufrimiento colectivo. Heins y Langenohl (2011) arguyen que el sufrimiento experimentado por los alemanes durante la Segunda Guerra Mundial, pese a que fue de una magnitud excepcional, con más de cinco millones de soldados alemanes muertos, más de un millar de ciudades y pueblos afectados, alrededor de seiscientos mil civiles alemanes muertos y más de 1 500000 mujeres violadas, no logró convertirse en un trauma cultural aceptado por los demás países, incluso años después cuando Alemania había logrado convertirse en una de las economías más fuertes y poderosas de Europa. Gao (2011) sugiere una explicación parecida para la reconstrucción maoísta de la nación china. A pesar de la pérdida de tres millones de chinos en combate y de más de tres millones de civiles dados de baja en la Guerra de Resistencia contra Japón entre 1937 y 1945, la tragedia permaneció en el ámbito privado e individual (p.53). Lo anterior, según Gao, fue consecuencia del bloqueo hecho por un trauma cultural universal: la lucha de clases de la china maoísta. Esta lucha opacó el surgimiento de una narrativa que permitiera ver al japonés como el enemigo de los chinos y fue reemplazada por una lucha entre el burgués y el proletario.

Las voces de las víctimas también generan narrativas distintas. En Colombia, como se mostrará en el acápite seis, las víctimas han cambiado la narrativa de trauma, apelando a referentes propios que muestran su lucha por salir del rótulo de víctimas para mostrarse como agentes políticos y culturales capaces de transformar su dolor en iniciativas de reconstrucción. Estas voces crearon lo que se denominó narrativas alternativas.

\section{4 ¿Qué son, a grandes rasgos, las narrativas alternativas?}

Las narrativas alternativas surgen a partir de las voces que tienen menos probabilidad de difundir sus mensajes a través de medios masivos. Por ejemplo, en el caso del holocausto judío, fueron los israelíes los que 
protagonizaron el proceso de trauma cultural, permitiendo que la lucha por el territorio palestino fuera justificada por ser los israelíes una generación que, salida del holocausto, merecía renacer en un nuevo territorio. La inscripción del sufrimiento del pueblo judío en la narrativa del holocausto "ha provisto de justificación la resistencia violenta contra todo lo que se percibe como amenaza externa" (Alexander y Dromi, 2011, p.119). En ese escenario ha surgido una reconstrucción simbólica en la que el pueblo palestino ha creado una contra-narrativa (o narrativa alternativa) en la que muestra cómo también ha sufrido la dominación occidental/israelí. Se muestra entonces como un movimiento heroico anticolonial por la liberación (p.121). Esto ha hecho que un grupo más amplio de intelectuales occidentales y autocríticos israelíes se identifiquen con los palestinos.

Las narrativas del sur creadas especialmente por grupos indígenas (De Sousa Santos, 2012) también pueden considerase narrativas alternativas. Estas muestran, a través de semánticas y lenguajes diferentes, la capacidad de crear concepciones y cosmovisiones propias que se alejan de las narrativas que propone la racionalidad occidental. Las narrativas del sur han creado una cultura política emancipatoria (2014) que debe sobrepasar la cultura indolente, institucionalizada en todos los niveles de educación y en la historia, escrita siempre por los vencedores. Para ello, se debe ampliar el valor simbólico de las luchas de quienes resisten las injusticias diarias.

Existen otros estudios empíricos que muestran la forma en la cual las comunidades crean sus propios conceptos y concepciones sobre su historia, por lo que también hacen parte de las narrativas alternativas. En Colombia, los estudios de Jimeno et al. (2008; 2009) logran mostrar cómo la comunidad de El Naya habla sobre la masacre que sufrieron en el 2001, y cómo son las víctimas las que a veces evitan un recorte de la 
verdad de los hechos (p.170). Para los habitantes de El Naya, el perdón no es un mecanismo mediante el cual se puede reconstruir comunidad, ni tampoco lo señalan como elemento relevante para expandir sus códigos culturales: “¡Se vive, se siente, El Naya está presente!”; “¡Ni perdón, ni olvido!” (p.189), gritaban durante la conmemoración. "Por la vida y la dignidad de los pueblos. Ni perdón, ni olvido" (p.190). La resistencia al perdón emerge como una contranarrativa a las difundidas por los medios de comunicación y los miembros del Gobierno.

\section{Breve historia del perdón jurídico en Colombia}

Colombia es un país que ha tenido un conflicto armado por más de sesenta años, generando una profunda crisis humanitaria. Según la Unidad para la Atención y Reparación Integral a las Víctimas (2017), el conflicto colombiano ha dejado desde 19858504127 víctimas, 7243 838 desplazados, 36015 secuestrados; 167554 desaparecidos; 2294 sindicalistas asesinados entre 1978 y 2012; 10272 víctimas de minas desde 1990, y 2087 masacres entre los años 1983 y 2011 (Proyecto Víctimas, revista Semana, 2013).

Si bien la mayoría de los colombianos hemos sentido la guerra de una u otra forma, esta no ha afectado a todos de la misma manera: la guerra ha recaído "especialmente sobre las poblaciones empobrecidas, sobre los pueblos afrocolombianos e indígenas, contra los opositores, y afecta de manera particular a las mujeres, a los niños y niñas" (Centro Nacional de Memoria Histórica, 2013, p.25). Los más perjudicados se encuentran concentrados en cien municipios de los 1123 que conforman el país, siendo los más afectados aquellos con una estructura rural atrasada y de colonización (Valencia y Velásquez, 2009). 


\subsection{De las amnistías y perdones incondicionados}

En Colombia, desde la época republicana hasta la actualidad se han propuesto más de doscientas amnistías ${ }^{5}$ e indultos que no lograron reconciliar a los colombianos (Aguilera, 2012). Las iniciativas políticas para terminar o suspender las guerras fueron tan abundantes como las mismas batallas: "A la par con los lenguajes políticos de los agravios, la sangre derramada, la tiranía y la conspiración, corrieron parejos los del perdón y el olvido, la clemencia y la reconciliación” (Uribe, 2003, p.31).

En numerosas ocasiones, las estrategias jurídicas de amnistías e indultos se asociaron con el comienzo de un nuevo orden institucional:

En 1832, sin que mediara un conflicto armado de por medio, fue aprobada una amnistía general para todos aquellos que tuvieran delitos políticos pendientes; de esta manera se celebraba la creación de la Nueva Granada [...] esta "ley de olvido", [...] estuvo pensada como una estrategia política para proyectar el imaginario de un nuevo comienzo (p.36).

Los órdenes institucionales nos enseñaron que el perdón no contribuyó a una verdadera reconciliación. Por el contrario, el perdón se expresó únicamente en la figura de amnistías, las cuales no evitaron que cada guerra civil fuera la continuación de una venganza por un conflicto precedente:

Las amnistías incondicionales a la terminación de los conflictos, sin que se hubieran establecido responsabilidades, ni esclarecido la verdad de lo

5 "La amnistía descriminaliza al olvidar el carácter delictivo en tanto que el indulto despenaliza sin olvidar este carácter. Con la amnistía desaparece la figura del delincuente en tanto que con el indulto se conserva" (Afanador Ulloa, 1993, p.14). "La amnistía se produce en el desarrollo de dos procesos: uno, en el de una victoria militar contundente dadas las condiciones de asimetría” (pág. 13) de un contendor frente a otro. "En este caso se busca la reinserción del vencido perdonando sus delitos a través de la amnistía, para poder vivir en paz. El otro caso es la indefinición del conflicto por la simetría entre contendores. Este caso deviene en negociaciones para superar el conflicto que traen la amnistía como medio de consecución de la paz” (p.14). 
ocurrido, ni reparado a las víctimas, mantuvieron sentimientos de injusticia y venganza que alimentaron posteriores guerras y violencias (Fisher, 2001, p.44; Uprimny, 2006, p.26).

La opinión pública ha jugado un papel importante en esta historia de perdón, ya sea sirviendo de apoyo para las voces dominantes a través de los medios de comunicación, o por el contrario, manifestando las voces alternativas. En los comienzos de la época republicana, hubo algunas voces que expresaron su inconformidad con las estrategias jurídicas de amnistía e indulto, especialmente porque representaban una debilidad inaceptable por parte de los vencedores, quienes querían castigo para los rebeldes y así evitar su reincidencia:

Su Excelencia el Jeneral Mosquera, rompió el año con una de aquellas providencias estepitosas [...] que son tan de su jénio. Hablamos del decreto de amnistía publicado en la Gaceta extraordinaria, N. ${ }^{\circ}$ 1,020. [...] Tenemos la pena de no aprobar esas gracias, esos jubileos plenísimos, o si se quiere, esas bendiciones papales intempestivas ( $\mathrm{La} \mathrm{Voz} \mathrm{del} \mathrm{Pueblo,} \mathrm{Bogotá,} 7$ de enero de 1849, p.3).

Al culminar el siglo XIX e iniciar el siglo Xx con la Guerra de los Mil Días, el 21 de noviembre de 1902 se instauró otra amnistía, la cual tenía como función "crear las condiciones de renegociación de las clases dominantes en procura por parte de las fracciones excluidas de su inserción en el aparato burocrático del Estado" (Sánchez, 1985, p.221). A estas medidas les siguieron los perdones de 1907 y 1908. Las amnistías continuaron siendo un puente entre los conflictos. Desde 1948 han sido utilizadas para "iniciar o finalizar los procesos de diálogo y negociación de los conflictos armados internos originados en la confrontación político-militar con los grupos guerrilleros que de alguna manera amenazaron con una toma insurreccional del poder del Estado" (Afanador Ulloa, 1993, p.7).

Así, en 1948 se sancionó la Ley 82 del 10 de diciembre, por medio de la cual los condenados en delitos contra el régimen constitucional, cometidos 
el 9 de abril de ese mismo año, quedarían “perdonados” (Molano, 1980). Según Sánchez (1985), los objetivos de esta amnistía incondicionada más que militares fueron político-ideológicos, pues se usaron para mitigar los efectos de la insurrección del 9 abril y no para frenarla. Básicamente, la amnistía se usó para congraciarse con los liberales que colaboraron en el apaciguamiento de la rebelión y no para contrarrestar las verdaderas causas de la rebelión. En estos casos se confundió la amnistía "como mecanismo para poner fin a la confrontación armada, con la solución a las causas que habían originado la guerra” (p.223). Precisamente, el error fue el mismo de siempre: confundir "la lucha por la democracia política" sin ligarla a "la lucha por la democracia económica y social” (p.251).

Lo mismo sucedió cinco años más tarde, cuando el general Rojas Pinilla (1953-1957) promulgó el Decreto 2184, creado para cobijar a los militares implicados en el fallido golpe de 1944 contra López Pumarejo, y luego, el Decreto 1823 expedido el 13 de junio de 1954 que cobijaba a los presos políticos, miembros de grupos guerrilleros, y extendía su efecto a grupos paramilitares denominados "guerrilleros de paz" (Molano, 1980; Villar Borda, 1982). Esto, como la historia ya lo había mostrado, no garantizó una paz duradera ni evitó la ola de violencia durante 1955-56. Tampoco evitó el ambiente de desconfianza derivado de las muertes de muchos desmovilizados que fueron asesinados ${ }^{6}$ por fuerzas oscuras durante el gobierno del Frente Nacional.

El ambiente de desconfianza llevó al presidente Alberto Lleras Camargo (1958-1962) a privilegiar la pacificación como el objetivo central de su gobierno y a crear una amnistía para apoyarla (Decreto 328 de 1958). En este caso, la opinión pública respaldó una política de perdón y olvido. Una revisión de los editoriales y columnas de periódicos de la época como El Espectador, El Tiempo, La República y El Siglo, entre 1957 y 1962, muestra que las élites detrás del Frente Nacional se aprovecharon

6 Por ejemplo, el 6 de junio de 1957 mataron a Guadalupe Salcedo a pesar de que había recibido amnistía absoluta. La misma suerte la corrieron otros ex jefes guerrilleros como Álvaro Parra (Sánchez, 1985, p.271). 
de sus vínculos con la prensa para difundir un discurso de "perdón y olvido”. El lema más repetido en más de doscientas editoriales entre 1957 y 1962 fue la famosa tríada de "paz, reconciliación y olvido” (Schuster, 2009 , p.14). Tan solo hubo un total de veinte contra voces.

El Decreto 328 de 1958 prometía “perdón y olvido” de manera implícita, privilegiando únicamente a los dos partidos políticos tradicionales, Liberal y Conservador, pues cobijar a los comunistas o a los responsables del 9 de abril de 1948 era impensable para la visión conservadora (p.99). Un somero análisis de esa época muestra que la impunidad reinó y las víctimas vieron las leyes de amnistía como otro golpe "traumático y doloroso” hacia ellas: “sin reparación material y simbólica, sin canales institucionalizados para discutir lo sucedido, los trabajos de la memoria y la rehabilitación de las víctimas estaban condenados al fracaso" (Schuster, 2009, p.22). En el pasado, "las élites prefirieron el olvido a la confrontación de las causas del conflicto. Es así como la 'paz', nacida de amnistías e indultos, carece de sustentabilidad” (p.24).

Durante el gobierno de Julio Cesar Turbay (1978-1982) se expidió la Ley 37 de 1981, que amnistiaba a todos los colombianos que hubieran cometido delito de rebelión, sedición y asonada y delitos comunes conexos antes de la vigencia de dicha ley. Esta norma no produjo efectos para la paz, en parte, porque no hubo un diálogo con los grupos insurgentes y quizás porque se condicionó a la entrega de armas y la reincorporación a la vida civil (Chaparro, 2013). La respuesta de los grupos guerrilleros no fue favorable para el gobierno. "La ley de perdón y olvido condicionado parecía más encaminada a calmar inquietudes de la opinión pública nacional e internacional en torno a la violación de derechos humanos que a un intento real por buscar la paz" (Ramírez y Restrepo, 1988, p.76). Fue así como la amnistía fracasó. La Corte Suprema de Justicia la declaró inconstitucional.

Ante este revés, Turbay buscó otra opción: la Comisión de Paz. Esta comisión tenía tres objetivos: la defensa de los derechos humanos, la desmovilización de los grupos guerrilleros a cambio de perdón incondicional 
del Estado y la trasformación económica de las regiones afectadas por la violencia (p.79). El perdón aparece de nuevo. Turbay lo utilizó para recuperar las riendas del país: treinta días de suspensión de actividades militares en los cuales los guerrilleros que se entregaran se beneficiarían de un indulto. De nuevo, la aceptación por parte de los grupos subversivos no fue la esperada por el gobierno.

La violencia continuó y en 1982 el presidente Belisario Betancur (19821986) buscó otro mecanismo para la paz que parecía no estar centrado en el perdón, sino en la negociación. Una de sus primeras acciones significativas hacia la consecución de la paz fue el restablecimiento de la Comisión de Paz, disuelta por el gobierno anterior, con el fin de nacionalizar la paz (Behar, 1985). No obstante, el 23 de septiembre de 1982 el perdón volvía a sonar en el discurso nacional: “El presidente expresó la necesidad de adelantar un plan de desarrollo para lograr la paz partiendo de una amnistía” (Afanador Ulloa, 1993, p.90). Se promulgaron el Decreto 474 de 1982, la Ley 35 de 1982 y la Ley 49 de 1985.

La Ley 35 de 1982 otorgaba perdón incondicional y olvido para los alzados en armas, cesación de procedimientos judiciales y libertad inmediata para todos los presos políticos. El perdón era protagonista otra vez: "Trazamos una línea cauterizante entre el pasado padecido que nos separaba y nos dividía, sobre el cual tendemos todos hoy un manto de perdón y olvido” (Betancur, 1984, citado por Ramírez y Restrepo, 1988, p.94).

La sociedad civil recibió favorablemente la amnistía. El diario La República exaltó la medida. El Espectador lo respaldó: "Para el partido Liberal, flote en las manos que flotare, la amnistía es un compromiso político y moral”. El periódico El País expresó: “Lo contrario (no ofrecer la amnistía) sería un acto de insensatez, que tiene un costo social, que casi siempre coincide con el precio de la libertad". El diario El Pueblo la mostró como un acto generoso del gobierno. Y El Siglo dijo que la amnistía abriría las puertas de la convivencia pacífica (Ramírez y Restrepo, 1988, p.108). Las Fuerzas Armadas no lo vieron igual. Para ellos, 
el perdón y el diálogo significaban la derrota ante los grupos armados. No obstante, debido a la aceptación popular de la propuesta, decidieron apoyarla (p.108).

En esta misma línea, el 4 de junio de 1985 el Congreso aprobó la Ley 40 , por la cual se concedió un indulto a aquellos condenados o procesados por delitos de sedición, rebelión, asonada y delitos conexos. Este mismo año se daría la fatal toma del Palacio de Justicia, acción que deslegitimó al M-19 y lo llevó a firmar la paz con el Gobierno cinco años después y a pedir perdón diez años más tarde. Al respecto, Vera Grabe pronunció las siguientes palabras de perdón:

[...] pedimos perdón a las víctimas de esta tragedia, a sus familiares y amigos, por la parte de responsabilidad que nos corresponde. [...] (Quiero) que podamos decir que el 7 de noviembre de 1995 hubo un acto de perdón que abrió la puerta para que los niños y niñas de este país se metieran en la construcción de una paz verdadera para toda Colombia (Grabe, 2001; Gómez Gallego et al., 2010, p.329).

Navarro Wolff también diría: “Por esos hechos, el M-19 les pidió perdón a todas las víctimas inocentes, a sus familiares y al país. Yo quiero repetir hoy esa solicitud de perdón. Y reconozco que, por mucho perdón que pidamos, nunca será suficiente” (Navarro Wolff e Iragorri, 2004, citados por Gómez Gallego et al., 2010, p.330). El presidente Betancur y el exministro Enrique Parejo González también expresaron la necesidad de pedir perdón: "El Ejército tiene que pedirles perdón a las víctimas, el primer obligado debió ser el ministro de Defensa y en algún sentido todos nosotros les debemos pedir perdón a las víctimas” (Gómez Gallego et al., 2010, p.351).

La amnistía no logró sostener la paz y el perdón salió del discurso público por unos años hasta las negociaciones en cabeza de Virgilio Barco (1986-1990). Durante su gobierno, el Congreso promulgó la Ley 77 de 1989, en la que se daba indulto o cesación de procedimiento y auto 
inhibitorio para delitos de rebelión, sedición, asonada y delitos conexos con los anteriores.

En el siguiente periodo presidencial, el gobierno de César Gaviria (19901994) se apoyó en una Asamblea Constituyente, con un papel activo de las guerrillas desmovilizadas. En su gobierno se dieron varias amnistías (Decreto 206 de 1990, Ley 0213 de 1991, Decreto 1833 de 1992, Decreto 264 de 1993 y Decreto 1495 de 1993) que ofrecían perdón tanto a quienes habían cometido delitos políticos como a quienes habían cometido delitos comunes. La concesión de estos perdones pudo haber respondido a la necesidad del Estado de reclamar el monopolio de la fuerza en el territorio nacional, frente a la evidente debilidad institucional para manejar a los nuevos actores de violencia surgidos, especialmente, del narcotráfico (Aguilera, 2012).

Pese a la amplitud jurídica — para algunos, impunidad- con que se manejó el conflicto en ese periodo, "el tándem Barco-Gaviria funcionó para unos cuantos grupos pequeños pero claves, como el M-19, Quintín Lame y el EPL” (Chernick, 2012, p.16). Estos se desmovilizaron y firmaron la paz. Las FARC y el ELN, por su parte, rechazaron ese modelo de negociación.

Durante el gobierno de Samper (1994-1998) se expidió la Ley 418 de 1997 que beneficiaría grupos armados que tuvieran un estatus político, como el que se le dio ese año al ELN. Esta ley incluía una limitación a las anteriores amnistías disfrazadas: "la exclusión para delitos graves de acuerdo con el derecho internacional por primera vez en la historia nacional” (Chaparro, 2013, p.117).

En el siguiente gobierno, el presidente Pastrana Arango (1998-2002) logró un acercamiento inicial con las FARC a través de una "amplia agenda de negociación” (Chernick, 2012) que extendió por tres años la vigencia de la Ley 418 de 1997. "La falta de resultados concretos de las negociaciones condujeron a la opinión pública a buscar la opción de la derrota militar a los insurgentes con Álvaro Uribe en la presidencia” (Chaparro, 
2013, p.118). Esto implicó un cambio muy fuerte en las narrativas de la opinión pública: se dio una "lucha del bien contra el mal, una confrontación de valores últimos” (Cuéllar, 2009, p.251).

Paradójicamente, a la par de la bandera gubernamental militar del presidente Uribe (2002-2010), basada en la confrontación armada con las guerrillas, se infiltró el discurso del perdón a través de la Ley 782 de 2002, el Decreto 128 de 2003, la Ley 975 de 2005, la Ley 1312 de 2009 y la Ley 1424 de 2010, que ofrecieron indulto por delitos comunes y políticos. El proceso de justicia transicional aplicado a los paramilitares se caracterizó por "amnistías disfrazadas" o "encubiertas": esa intención se reflejó desde el procedimiento inicial seguido con los 31671 desmovilizados, pues de ellos apenas 3635 fueron postulados para ser procesados por la ley de justicia y paz, mientras que a los restantes 28 036 se les concedió la libertad (Aguilera, 2012, p.18).

En julio de 2007, once mil paramilitares habían sido exonerados y diecisiete mil estaban a punto de serlo (Gallón, 2011). De esta manera, el discurso oficial centró sus esperanzas en el perdón, como lo manifestó el ex vicepresidente Francisco Santos (2002-2010). En una entrevista realizada por Yamid Amat (2005), Santos situó el perdón como elemento central para la reconciliación y para lograr un proceso de desmovilización exitoso: "Hay que perdonar. El país tiene que lograr una reconciliación y perdonar, si de verdad quiere la paz”.

Las amnistías han buscado la solución de un conflicto, pero no han sido acompañadas de fuertes campañas de defensa de los derechos humanos, ni de verdaderos cambios sociales. Por lo tanto, han sido equiparadas a formas de impunidad. Esto ha traído nuevas olas de violencia, nuevos odios y venganzas, y un sabor de injusticia social que permanece hasta nuestros días. Cada modelo de amnistía ha representado el comienzo de un nuevo "ciclo de violencia", poca inversión social, asesinatos y marginación política de los ex insurgentes. Esto, a su vez, propicia la regeneración de la insurgencia (Molano, 1980). Las amnistías en Colombia no han surgido en medio de victorias decisivas por parte 
de los contendientes, se ha tratado de treguas temporales, en las cuales las hostilidades se han prolongado por otros medios (Sánchez,1985).

\section{Metodología de la investigación}

Debido a la enorme cantidad de información disponible en la actualidad, analizar su contenido se ha convertido en una tarea compleja, lo que ha estimulado el uso de herramientas que indexen grandes colecciones de documentos. La mayoría de análisis se han centrado en datos binarios o cuantitativos. No obstante, datos cualitativos como los textos no han sido aprovechados en todo su potencial.

\subsection{Topic modeling: alcances y limitaciones del modelo}

Topic modeling es una de las metodologías utilizadas para analizar grandes colecciones de datos, haciendo uso de modelos de probabilidad e inferencia estadística (Bail, 2013; Blei, 2012; Blei et al., 2003; Griffiths y Steyvers, 2002, 2003, 2004). Con ello, se pueden establecer los patrones de temas en grandes colecciones de textos. En el caso del modelo más básico (Latent Dirichlet Allocation), se asume que cada documento está compuesto de distintos temas que el investigador nombra, cada uno con una probabilidad distinta. A su vez, cada tema está definido por palabras que tienen mayor probabilidad de coocurrencia ${ }^{7}$.

A pesar de las limitaciones del modelo ${ }^{8}$, la metodología de análisis permite la clasificación de textos y el descubrimiento de nuevos patrones antes desconocidos por el investigador por la magnitud de los datos.

7 Un tema como dinero tiene mayor probabilidad de contener palabras como banco, liquidez, consumo, transacción, ahorro o deuda, que palabras como agua, fluvial, flujo, vegetación, peces, las cuales tienen mayor probabilidad de componer un tema como río. Una palabra puede estar en varios temas, pues el modelo permite polisemia (Griffiths y Steyvers, 2007).

8 Uno de los supuestos de modelo es que no importa el orden de las palabras dentro del documento, sino la probabilidad con las que estas conforman el mismo. Esta es una de las grandes limitaciones de la metodología. Griffiths y Steyvers. 2007 presentaron una extensión del modelo que supera la limitación. Además, a la hora de definir temas el investigador supera esta limitación. 
Por ejemplo, Nelson (2011) analizó 112 mil artículos de prensa del Richmond Daily Dispatch entre noviembre de 1860 y diciembre de 1865, con casi 24 millones de palabras para explorar y descubrió los cambios que se dieron en la vida social y política de los habitantes de Virginia a causa de la Guerra Civil de Richmond. También Blevins (2010) analizó el diario de Martha Ballard y encontró patrones emocionales en la vida de esta mujer del siglo xviII que en un primer momento no parecían relevantes en la investigación.

\subsection{Descripción de fuentes}

En la presente investigación se analizarán artículos de prensa de dos de los diarios más importantes del país, El Tiempo y El Espectador, y de la revista Semana, entre 2008 y 2015. En este periodo, el discurso sobre el perdón tomó relevancia en la agenda periodística, aunque venía aumentando desde el 2004, cuando ya sonaba la Ley de Alternatividad Penal que devino en la Ley de Justicia y Paz en el 2005.

\subsection{Análisis de prensa}

Para la investigación se creó una base de datos con 1407 artículos publicados entre 2008 y 2015: 392 de El Tiempo $^{9}$, 451 de El Espectador ${ }^{10}$ y 564 de la revista Semana ${ }^{11}$. Para analizarlos se aplicará la metodología de topic modeling. En cada uno de los medios analizados se encontraron distintos temas. Estos se construyeron a partir de palabras que tendieron

9 Corresponden a una muestra aleatoria del $40 \%$ de las noticias encontradas. El Tiempo es considerado como uno de los periódicos más influyentes del mundo y catalogado como uno de los seis mejores diarios de Latinoamérica. Su tirada es de 260 mil ejemplares. Tiene 140 mil suscriptores y reparte a ocho mil puntos de venta (Estructura de la comunicación de Colombia, 2006).

10 Corresponden a una muestra del $70 \%$ de las noticias encontradas. Actualmente, $E l$ Espectador imprime cuatro ediciones diarias y su tiraje es de 220 mil ejemplares, llegando hasta los 280 mil los domingos (Estructura de la comunicación de Colombia, 2006).

11 Corresponden a una muestra del $70 \%$ de las noticias encontradas. Es una de las revistas más prestigiosas de Colombia (Banco de la República, 2015). 
a salir juntas con mayor probabilidad. Por ejemplo, a partir de palabras como justicia, paz, ley, marco, jurídico, gobierno, política, transicional, Congreso, amnistía, Farc, perdón, se definió el tema "Marco Jurídico para la Paz”. Hablar de La Habana, por ejemplo, implicó que palabras como proceso, paz, gobierno, Habana, Farc, Santos, guerrilla, acuerdo, mesa, negociación, o diálogos aparecieran juntas.

Dichos temas se fueron transformando en el tiempo, como lo muestra la figura $1^{12}$. En ella se muestra que los temas de perdón cambiaron de acuerdo a coyunturas. Por ejemplo, en el 2008 la discusión giró en torno al rescate de los secuestrados en la Operación Jaque y al tema del secuestro, especialmente por miembros de las FARC y del ELN, como una violación a los derechos humanos reconocidos internacionalmente. Una de las noticias que sonó ese año fue con respecto a la propuesta del presidente Uribe de "otorgar la libertad y dar una recompensa a guerrilleros que abandonen las filas insurgentes trayendo con ellos a secuestrados" (Semana, 11 de diciembre de 2008). Esto fue fustigado por Amnistía Internacional ya que no puede haber amnistías o perdones para quienes han cometido abusos de derechos humanos o han violado el Derecho Internacional Humanitario.

Para el 2009 y el 2010, los temas de perdón se ocuparían de dos acontecimientos importantes: por un lado, el perdón pedido por el hijo de Pablo Escobar (ahora llamado Sebastián Marroquín) a los hijos del candidato a la presidencia Luis Carlos Galán y a los hijos de Rodrigo Lara Bonilla, ambas víctimas del Cartel de Medellín. Por otro lado, en el 2010, la agenda sobre el perdón fue ocupada por el fallo de la Corte Interamericana de Derechos Humanos emitido ese mismo año, en el que se condenaba al Estado colombiano por el asesinato del senador Manuel Cepeda. En ese caso, el Estado colombiano, representado por el entonces ministro del Interior Germán Vargas Lleras, debió reconocer en acto

12 Este gráfico incluye las diez palabras con mayor probabilidad que formaron cada uno de los ocho temas (uno por cada año) más sonados en los tres medios analizados. 
público, el 9 de agosto de 2011, día en que se cumplían diecisiete años del asesinato del senador, su culpabilidad en el crimen.

En el 2011, se empezó a relacionar el perdón con el Marco Jurídico para la Paz. Este acto legislativo fue aprobado el 14 de junio del 2012, pero desde el año anterior ya se venían escuchando voces al respecto ${ }^{13}$. Este marco jurídico facilitaría la desmovilización, pero pondría en entredicho la capacidad de los organismos para hacer justicia. "Locos por la paz", "Es mejor un desmovilizado que una baja" y "Salvavidas para desmovilizados", son algunos de los titulares que dan cuenta del perdón en el 2011.

En el 2012, el tema central sobre el perdón lo ocupó el Palacio de Justicia. En ese caso el protagonista fue el coronel Alfonso Plazas Vega, ya que el Tribunal Superior de Bogotá ratificó su condena a treinta años de prisión por su responsabilidad en la "recuperación" del Palacio. El Ejército debió pedir perdón en un acto público en la Plaza de Bolívar, mismo escenario del holocausto del Palacio de Justicia. El debate sobre el fallo de perdón se dio en parte por las declaraciones del presidente Juan Manuel Santos, en las que manifestaba que a quien se debía pedir perdón era al presidente Belisario Betancur. Lo que llama la atención sobre los artículos son las pocas referencias a las víctimas (el $2 \%$ ), quienes fueron desplazadas en el discurso por referencias al Estado, al presidente y al Ejército (40\%). También es significativo la figura de un antihéroe, sobre el que recae toda la culpa, pese a que este no actuó solo.

En los siguientes años (2012-2015), las referencias al perdón se centraron en las negociaciones de La Habana. Palabras como Farc, guerrilla, proceso, acuerdo y mesa de negociación fueron protagónicas. La figura 1

13 Por ejemplo, el senador Roy Barreras se pronunció sobre el interés del gobierno en "ganar todo en verdad y reparación, y algo en justicia". Se refería a la creación de un nuevo marco legal que permitiera futuras desmovilizaciones para lograr una paz que "la aplicación rígida de la justicia" dificultaba en países que enfrentan conflictos (Semana, 21 de enero de 2011). 
muestra la evolución de este tema en los años estudiados. Dentro de las noticias analizadas, el discurso va cambiando hacia el 2014, cuando ya se piden actos simbólicos de perdón vistos como "actos de contrición”, gestos de "verdadera voluntad" y precedentes de acciones concretas como la entrega de armas para la búsqueda de la paz. Desde ese momento, se habla del "ánimo de perdón y reconciliación con las víctimas”, pese a que muchas de estas se sienten incómodas cuando se pide un perdón sin responsabilidad jurídica.

En el marco de La Habana aparecen dos noticias que ponen como protagonistas a algunas de las víctimas del conflicto. En este caso, una de ellas hace referencia al "primer acto serio de contrición" con las víctimas de Bojayá14. En un encuentro con ellas, "Pablo Catatumbo", negociador por las FARC, dijo que estarían dispuestos a repararlas:

Ahora, cuando estamos dialogando para construir la paz con verdad y justicia, debemos expresar [...] que sentimos un profundo pesar. Declararlo hoy no repara lo irreparable [...] ni borra el sufrimiento generado a tantas familias, sufrimiento del cual somos conscientes y por el que ojalá seamos perdonados (El Espectador, 18 de diciembre de 2014).

Pese a que este es un acto simbólico muy positivo, según el mismo presidente Santos, tampoco podemos aventurarnos a concluir que este acto desencadenó una serie de acciones y símbolos de reconciliación, pues tampoco se generaron otros contextos de perdón como días después lo reclamó el alcalde de Medellín, Aníbal Gaviria, en una entrevista a Víctor Andrés Álvarez, corresponsal de El Tiempo en esta ciudad: “¿A unos sí y a otros no? [...] Me parece un gesto que hay que valorar, [...] pero no dejo de reconocer que el perdón debe ser a miles de víctimas de las FARC” (El Tiempo, 22 de diciembre de 2014).

14 Ver acápite 4.1.2 para una descripción de Bojayá. 


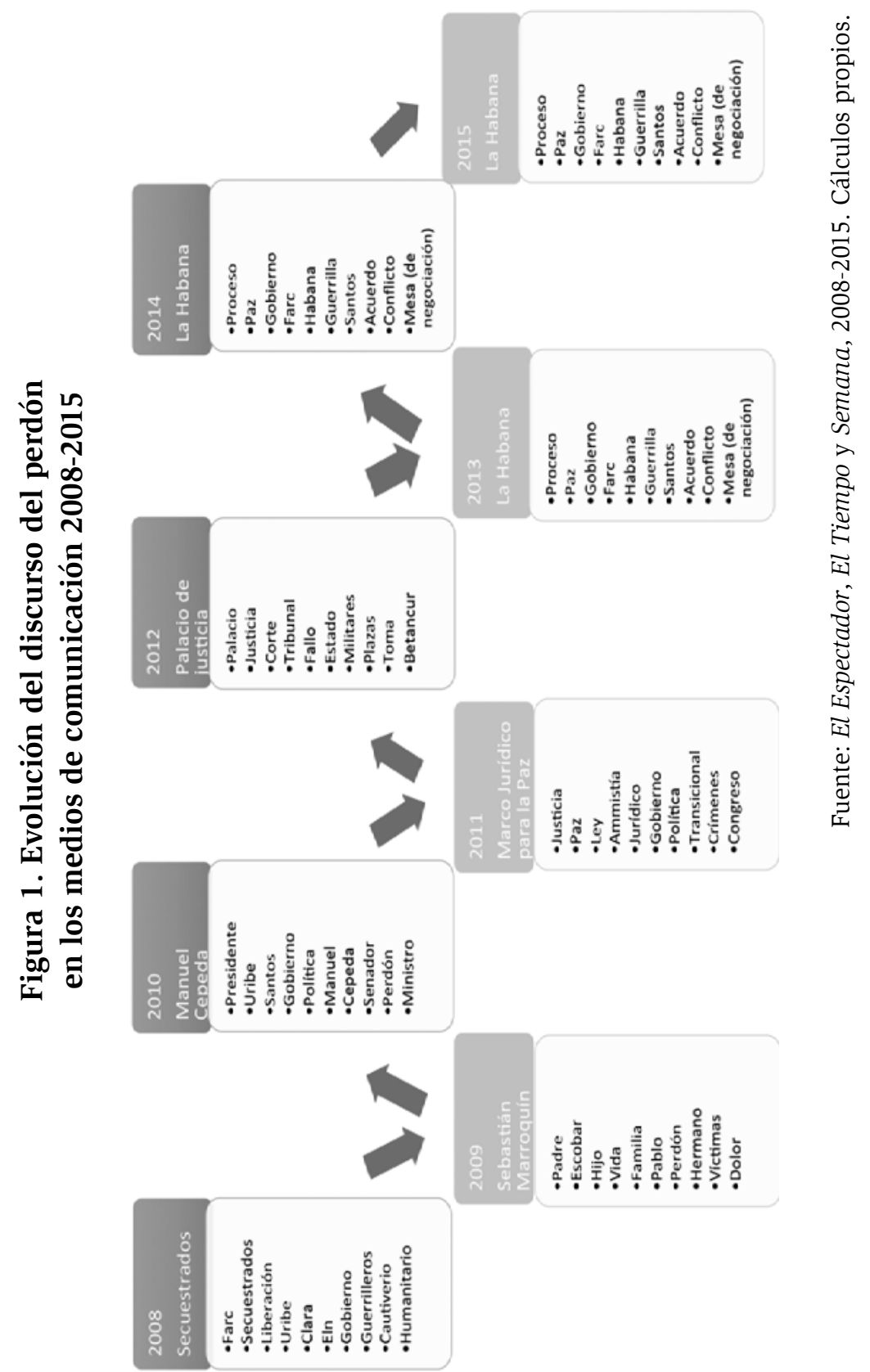




\section{Casos emblemáticos: ¿cuáles son las narrativas de los sobrevivientes? ${ }^{15}$}

Para contrastar estas referencias se analizarán —utilizando la metodología de topic modeling - testimonios de sobrevivientes que han reconstruido su vida después de episodios traumáticos. Estos testimonios corresponden, esencialmente, a cuatro casos emblemáticos de violencia documentados por el Centro Nacional de Memoria Histórica (CNMH), entidad que me facilitó parte de los testimonios aquí analizados. Además de ello, la investigación se nutrió de extractos de relatos de las víctimas publicados por el mismo centro, y de testimonios disponibles en videos de carácter público, obtenidos en YouTube. Estos testimonios se dividen por casos: 172 de San Carlos, 50 de Bojayá, 50 de Trujillo y 169 de Mapiripán. Estas narrativas constituyen lo que he denominado discursos alternativos.

\subsection{Cuatro casos de reconciliación: breve contextualización}

A continuación, se hará una breve explicación y contextualización de cada uno de los casos emblemáticos con el fin de mostrar sus rasgos más particulares:

\subsubsection{Trujillo}

Este municipio, ubicado al noroccidente del departamento del Valle, vivió entre 1988 y 1994, junto con los municipios de Bolívar y Riofrío, masacres perpetradas por estructuras narcotraficantes, la Policía y el Ejército, que dejaron "342 víctimas de homicidio, tortura y desaparición forzada”. En el corregimiento La Sonora, ocurrió “la desaparición de los ebanistas, el asesinato del sacerdote Tiberio Fernández y la

15 Este acápite ofrece la visión de algunas víctimas del conflicto armado, entendiendo que son heterogéneas y que la distinción entre víctima y victimario muchas veces es imposible de establecer. Por lo tanto, se reconoce que es solo una visión parcial del universo de sobrevivientes. 
desaparición de sus acompañantes” entre marzo y abril de 1990 (Centro Nacional de Memoria Histórica, 2011, p.17). Las víctimas de Trujillo reclamaron al Estado el reconocimiento de su responsabilidad en los hechos violentos ocurridos entre 1986 y 1994, pero el Gobierno solo aceptó su responsabilidad por los hechos acaecidos en 1990.

En consecuencia, para el caso de Trujillo, el número de víctimas que reclamaban las mismas (342) difería significativamente del número que reconocía el Estado (34). Esto motivó a que la Asociación de Familiares de las Víctimas de los hechos violentos de Trujillo (Afavit) solicitara la creación de un comité interinstitucional que esclareciera la verdadera responsabilidad del Estado (Comité de Evaluación de Casos de Trujillo - CECT-). El comité estaba integrado por ONG de derechos humanos, la Iglesia católica y la Defensoría del Pueblo. El resultado de este comité fue el reconocimiento de 131 víctimas. Ante ello, Afavit identificó que eran 245, haciendo de Trujillo un ejemplo de búsqueda de la verdad desde abajo.

\subsubsection{Bojayá: una mirada negativa de las FARC}

Bojayá es un municipio ubicado en el departamento del Chocó, cuya población fue víctima del conflicto armado, al encontrarse situado en medio de la lucha de grupos armados ilegales. Su cabecera municipal, Bellavista, estuvo sitiada en el 2002 durante varios días, permaneciendo indefensa su población (Centro Nacional de Memoria Histórica, 2010). Por ello, fue víctima de ataques indiscriminados con armas no convencionales como cilindros bomba, uno de ellos ampliamente conocido porque impactó en una iglesia, dejando más de 74 muertos $^{16}$. Esta población estuvo bajo el mando del comandante paramilitar conocido como “El Alemán”, quien se apropió de miles de hectáreas para sembrar palma africana. Las comunidades de Curvaradó, Cacarica y Domingodó mencionan por lo menos veintidós mil hectáreas que

16 El cilindro fue lanzado por miembros del Bloque 58 de las FARC, el 2 de mayo de 2002. 
fueron arrebatadas por los miembros del Bloque Elmer Cárdenas (Verdad Abierta, Conflicto armado en Colombia, s. f.).

El caso de Bojayá es interesante de analizar, pues a pesar de que el enfrentamiento se dio entre miembros de la guerrilla y de las AUC, la opinión pública centró su mirada en el papel de las FARC. Su accionar violento se convirtió en fuente de desprestigio más para ellos que para los paramilitares, pese a que estos últimos comparten responsabilidad. De acuerdo con la Oficina en Colombia del Alto Comisionado para los Derechos Humanos de la ONU, tanto los guerrilleros de las FARC como los paramilitares fueron responsables. Estos últimos, por participar en acciones bélicas en lugares donde pusieron en riesgo a la población civil. El Estado fue igualmente declarado culpable por no responder adecuadamente a las alertas tempranas hechas por la Defensoría del Pueblo el 24 de abril de 2002, y por no cumplir con su papel de garante de la vida de civiles en medio del conflicto.

La masacre de Bojayá tiene un papel importante dentro del conflicto, pues marcó un quiebre en la mirada hacia las FARC, deslegitimando aún más su accionar. A partir de allí, el tejido organizativo local y regional se ha convertido en "un referente para comprender los mecanismos que utilizan las comunidades para tramitar y mitigar los impactos de las violencias (Centro Nacional de Memoria Histórica, 2010, p.279). Un actor central en todo el proceso de reconstrucción social ha sido la Diócesis de Quibdó17, pues esta “es más visible que el propio Estado. Cuando el Gobierno quiere hacer algo, la diócesis ya está hace rato en ese problema” (Verdad Abierta, 2009). La Diócesis ha fortalecido los lazos al interior de la comunidad, ha fomentado la cultura del pacifismo,

17 La Diócesis de Quibdó fue ganadora del Premio Nacional de Paz en el 2005, por su papel en la reconstrucción del tejido social (Verdad Abierta, 2008; Premio Nacional de Paz, 2008). Este premio es convocado por Semana, El Colombiano, El Tiempo, el Programa de las Naciones Unidas para el Desarrollo, Caracol Radio y Caracol Televisión, en el que entregan sesenta millones de pesos y un diploma de honor al ganador. 
la tolerancia y la esperanza, y ha ayudado a difundir los procesos de reconciliación al exterior (Verdad Abierta, 2009).

\subsubsection{Mapiripán: la responsabilidad del Estado}

La masacre de Mapiripán ocurrió entre el 15 y el 24 de julio de 1997, en la que según Carlos Castaño hubo 49 muertos y cinco mil desplazados. En estos hechos participaron el Ejército y los paramilitares (Video Contravía: Masacre de Mapiripán). El 12 de julio de 1997, miembros de las AUC aterrizaron en el aeropuerto de San José del Guaviare con permiso del Ejército. Este último también facilitó camiones para que los paramilitares se transportaran a Mapiripán, lo que contribuyó a que el 15 de julio más de cien hombres rodearan el municipio. Los paramilitares portaban armas cuyo uso solo era permitido para el Estado. El resultado, una matanza en el municipio. Esta masacre inauguró la penetración de las AUC en el departamento del Meta (Observatorio de Democracia de la Misión de Observación Electoral, 2007). Por estos hechos, el general Uscátegui fue condenado, luego absuelto, y finalmente se le revocó la absolución cuando la Sala de Casación Penal de la Corte Suprema de Justicia dejó en firme la condena a 37 años de prisión.

Por esta masacre, el Estado colombiano fue declarado responsable y tuvo que pedir perdón: “[El Estado] expresa su profundo respeto y consideración por las víctimas de los hechos ocurridos en Mapiripán entre el 15 y el 20 de julio de 1997, y evoca su memoria para lamentar y pedir perdón a sus familiares y a la sociedad colombiana” (Semana, 31 de octubre de 2011). Escuchar lo que tienen que decir las víctimas de la masacre de Mapiripán es relevante en la medida en que este caso pone de manifiesto la relación directa entre agentes del Estado y paramilitares y su responsabilidad conjunta en la masacre. Figuras antiheroicas como el general Uscátegui o el general Francisco Pedraza envuelven la mística del caso de Mapiripán. 


\subsubsection{San Carlos: caso ejemplar de reconciliación}

San Carlos es un municipio ubicado al nororiente antiqueño, el cual sufrió un fuerte episodio de violencia que lo convirtió en un municipio con altas tasas de desplazamiento y de minas antipersonales. Hace parte de la región del Oriente antioqueño, una de las cinco regiones de Colombia con mayor número de personas desplazadas por el conflicto armado entre 1997 y 2004. En ese lapso fueron expulsadas de esta región 125071 personas (Centro Nacional de Memoria Histórica, 2011, p.39). En San Carlos, entre 1985 y el 2009, por lo menos 19954 personas abandonaron su lugar de residencia.

Este lugar es un territorio que ha sido campo de interacción de la violencia producida por diferentes grupos armados ilegales. Entre 1988 y 2010 se produjeron allí 33 masacres, 219 personas asesinadas, 156 desapariciones forzosas, 78 personas fueron víctimas de minas antipersonales y 126 de asesinatos selectivos. Fue escenario de acciones violentas desde los años ochenta debido a su posición estratégica, pues se encuentra sobre una zona de embalses en donde se genera casi el $33 \%$ de la energía del país (Centro de Memoria Histórica, 2011, p.25) y por ello también ha sufrido la concentración de la tierra ${ }^{18}$. Esto atrajo tanto a multinacionales hidroeléctricas y entidades estatales (actores legales) como a grupos armados al margen de la ley (actores ilegales: FARC, ELN, paramilitares). Los actores, tanto legales como ilegales, pusieron sus ojos en la riqueza del territorio, aunque se dio más un proceso de extracción de recursos que de inversión en los habitantes de San Carlos. El interés en la riqueza dio paso a que el municipio fuera disputado por los diferentes grupos armados al margen de la ley, generando violencia dentro de la comunidad. A pesar de la heterogeneidad de grupos, el conflicto tuvo un punto de quiebre con la llegada de los paramilitares, que provocaron la migración de cerca de veinte mil de las 25840 personas que habitaban el municipio (Centro de Memoria Histórica, 2011).

18 El coeficiente de Gini es una medida de desigualdad que va de 0 (total igualdad) a 1 (concentración total). En el 2006, el coeficiente de San Carlos fue de 0.7275, uno de los más altos de la región (Prodepaz, 2010). 
En las épocas más crudas de la violencia, la presencia de la institucionalidad se vio menguada por los actores armados (FARC antes de 1999 y autodefensas en 1999), quienes declararon objetivo militar a los funcionarios de la alcaldía. Esto coadyuvó a que el tejido social y el crecimiento organizativo hasta entonces obtenido en San Carlos se deteriorara, lo que posteriormente motivó el desarrollo de iniciativas de recuperación del tejido social tan significativas en Antioquia. Casos como el Tejido Social Distante (Tesodi) ${ }^{19}$, encargado del primer paso de organización antes del retorno, y Centro de Acercamiento para la Reconciliación y la Reparación (Care) ${ }^{20}$, encargado de ayudar a las víctimas ya retornadas, fueron significativos.

Gracias a los esfuerzos de iniciativas como estas, en la actualidad San Carlos es uno de los primeros municipios de Colombia declarado libre de sospecha de minas antipersonal ${ }^{21}$ (Ministerio del Posconflicto, Derechos Humanos y Seguridad, 2015). Fueron las mismas víctimas las que gradualmente lograron que la institucionalidad se sumara a su iniciativa propia ${ }^{22}$.

\section{2 ¿Qué patrones encontramos?}

En los casos estudiados se pueden encontrar ciertos temas recurrentes. Los que más se mencionan son aquellos relacionados con procesos políticos, memoria, autogestión, justicia y reparación. El tema del perdón

19 Los representantes de la colonia de comerciantes de San Carlos llevaron una propuesta a la Oficina de Derechos Humanos de Medellín que buscó su reconocimiento y la aplicación real de la Ley de 387 de 1997, "por la cual se adoptan medidas para la atención de los desplazados internos por la violencia en Colombia” (Testimonio hombre, Fundación Tesodi, 23 de febrero de 2009).

20 El Care nació por iniciativa de una de las víctimas, Pastora Mira, concejal del municipio en 2015. Surgió de un cabildo abierto y terminó en la aprobación del centro como política pública del municipio en donde las víctimas podían generar propuestas (Gamboa, 2010; Care, 2007).

21 En San Carlos se despejaron 159 115,95 metros cuadrados (Geneva Call, 2013, pp.11-12). Los mismos habitantes de San Carlos explotaban las minas con la ayuda de una pitica que amarraban a diez metros de la misma.

22 El municipio recibió el Premio Nacional de Paz en el 2011, ya que "ante la incertidumbre y el desarraigo, cientos [habían] decidido retornar” (Premio Nacional de Paz, 2011). 
ocupa un papel menor, sin que esto signifique que las víctimas guarden rencor, no estén dispuestas a seguir con su vida o no quieran generar iniciativas de reconciliación. Sin embargo, existen otros asuntos más relevantes a la hora de reconstruir sus vidas de forma satisfactoria. La siguiente figura muestra los temas que las víctimas más mencionan, como aproximación para entender sus prioridades.

En las iniciativas de memoria, un ejemplo es el Jardín de la Esperanza. Este es un monumento en memoria y reparación de las víctimas de San Carlos, inaugurado en 2011. Está ubicado en el parque principal de este municipio con flores que llevan el nombre de cada víctima para recordarlas (San Carlos: Memorias del éxodo en la guerra, 2011). En Trujillo, el Árbol de la esperanza y las Esculturas de la reconciliación hechas en cemento han sido usados como herramientas de expresión para aflorar el rencor y la rabia. La idea de este proyecto fue volver a "vestir al familiar desmembrado, devolverle sus miembros” (Testimonio, mujer hija de víctimas, Trujillo una tragedia que no cesa, 2008).

\section{Figura 2. Temas relevantes para la superación del trauma}

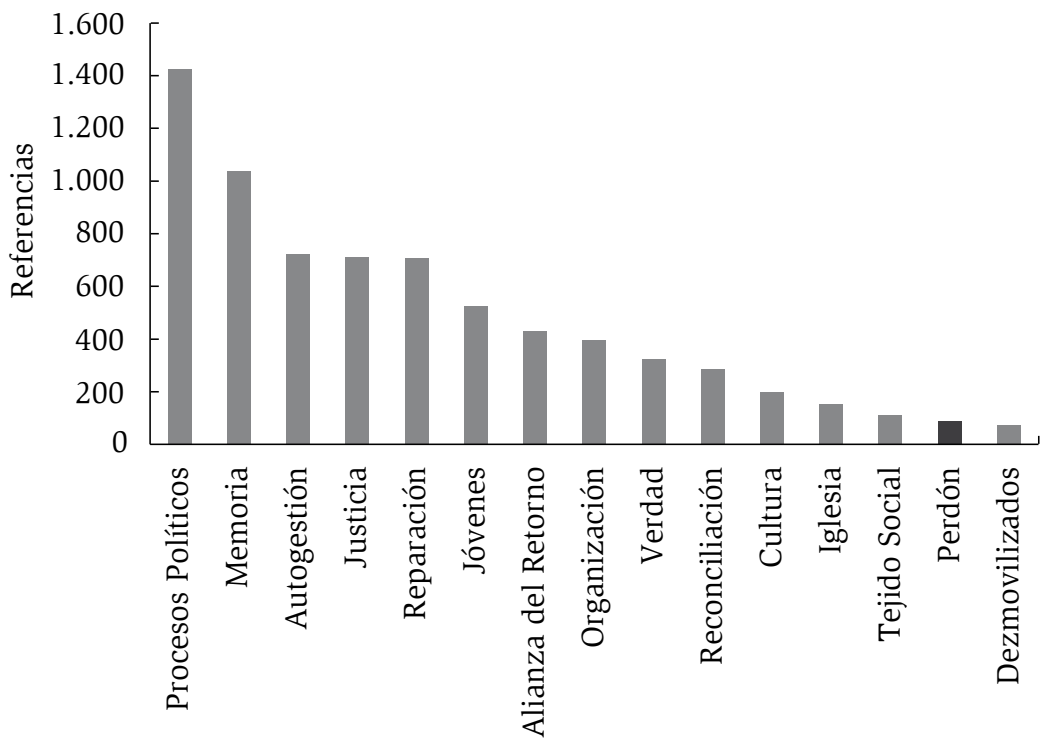

Fuente: Cálculos propios a partir de testimonios. 
Esto hace parte de la elaboración del duelo, ya que permite seguir recordando a quien ya no está. Así, se ha convertido el sitio en un lugar sagrado, porque allí se encuentran todas las imágenes, todo lo que eran las personas. Dentro de su proceso de exigencia de reconocimiento, la memoria del padre Tiberio ha sido importante. En la capilla construida en un montículo, como parte de la reparación del Estado, se encuentra un cuadro de un Cristo sin cabeza, tal como encontraron el cuerpo del padre Tiberio. A partir de allí se han zurcido historias en las que la memoria hace parte importante de la recuperación del tejido social. Asimismo, en el 2008, las víctimas empezaron a trabajar en la construcción de textos personales que relataran lo sucedido. En los textos realizados por víctimas o familiares, se encontró información biográfica, en la cual se resaltó el aspecto sentimental y humano de las víctimas. Otro ejemplo de memoria se encuentra en Bojayá: la iniciativa de Danzas Bojayá para recordar lo ocurrido. Con el apoyo de la parroquia San Pablo Apóstol de Bojayá, los niños y jóvenes han logrado transmitir un mensaje de memoria (Centro Nacional de Memoria Histórica, 2010).

En el tema de autogestión ${ }^{23}$ se encontraron referencias a la creación de organizaciones de víctimas y de la sociedad civil para proteger sus derechos. Estas han elaborado proyectos propios para tener mayor incidencia como sujetos políticos. Por ejemplo, el Foro Interétnico Solidaridad Chocó - FISCH - se creó con el objetivo de defender la dignidad y el territorio de los pueblos negros, indígenas y mestizos, a través de "la construcción de la autonomía comunitaria desde los consejos comunitarios y cabildos indígenas" (Corporación Nuevo Arco Iris, 2007, p.66). Con los procesos de autogestión, los sobrevivientes se convierten en verdaderos sujetos políticos al ser conscientes de sus derechos y reclamarlos como parte de su organización. En estos procesos se encuentran las marchas y todos los mecanismos que han hecho que la organización juegue un papel importante.

23 Compuesto por palabras como organización, proyectos, propios, incidencia, política, autonomía, comunitaria, territorio. 
El tema de justicia es recurrente ${ }^{24}$. Por ejemplo, una de las víctimas de la masacre de Bojayá señalaba que quiere que se haga justicia, aunque es consciente de que nadie podrá reparar la vida de quienes jamás regresarán. Para ella, la justicia implica "la identificación y asignación de responsabilidades al autor material, pero se deben hacer esfuerzos por identificar y sancionar a los autores intelectuales de los hechos" para que la condena no se haga a medias (Corporación Nuevo Arco Iris, 2007, p.92). Este tipo de exigencias están acompañadas de otras como la creación de instancias competentes que generen las condiciones necesarias para que miembros de grupos al margen de la ley reconozcan sus responsabilidades, tales como comisiones de la verdad o tribunales especiales.

La impunidad se convierte en otra forma de agresión a las víctimas, no solo por la ineficiencia de los recursos judiciales, sino porque a veces los victimarios cuentan con soportes políticos o mediáticos que les dan credibilidad y "ponen un sello de sospecha criminal a los reclamos de las víctimas” (Centro Nacional de Memoria Histórica, 2008, p.18). Esto hace que las víctimas se apoyen en ONG, en las iglesias, en los sindicatos o en Cortes internacionales como la CIDH. Por ejemplo, para el caso de Trujillo, la impunidad se evidenció en la desacreditación de un testigo, Daniel Arcila Cardona, aduciendo que tenía problemas mentales ${ }^{25}$, en la desaparición de pruebas, en las intimidaciones y en la criminalización de las víctimas como auxiliadores de la guerrilla.

El tema de la reparación ${ }^{26}$ es muy variado, pero en él se encuentran políticas importantes como la priorización de planes de retorno. Algunas

24 Compuesto por palabras como responsabilidades, autor material, sanción, impunidad.

25 "El presidente Ernesto Samper reconoció la plena responsabilidad del Estado por la masacre de 107 personas en Trujillo. Uno de los testigos del genocidio fue Daniel Arcila Cardona, quien después de fugarse denunció el hecho ante las autoridades. Medicina Legal lo declaró enajenado mental y su testimonio no fue tenido en cuenta. Arcila fue presuntamente asesinado en 1991" (Semana, 6 de marzo de 1995).

26 Compuesto por palabras como retorno, proyectos productivos, tejido social, derechos, vivienda. 
víctimas, como las de Bojayá o San Carlos, han manifestado que una reparación está ligada a la devolución de los proyectos productivos que tenían antes de haber sido vulnerados sus derechos. Por ello, la creación de empleo, la implementación de proyectos productivos, la construcción de viviendas y el apoyo a los procesos organizativos son propuestas claras de reparación (San Carlos, testimonio anónimo 1).

El tema de jóvenes fue importante en varios relatos. Por ejemplo, en San Carlos, existió una generación perdida de jóvenes que podían aportar mucho en la recuperación del tejido social. En ese caso, el Care, la Pastoral Juvenil y la Opción la Vida tuvieron un papel importante para apoyar el Comité Impulsor de Juventud. Este buscó una interlocución directa entre los jóvenes y otras instituciones, y visibilizó al joven dentro del municipio, también para que el joven fuera consciente de que es un actor político con derechos.

Para el referente del perdón no se encontraron referencias a este concepto. Es en Mapiripán en donde comparativamente se encontraron más referencias al perdón, por la exigencia que se le hizo al Estado de reconocer su responsabilidad en los hechos. Sin embargo, en los testimonios analizados, las víctimas poco hablan de perdón, sin que esto signifique que no trabajen en la superación del dolor y hayan dejado el rencor a un lado. Prefieren referirse más a la memoria, la autogestión, la justicia, la reparación, los jóvenes, el retorno o la verdad. Por lo tanto, el perdón puede estar jugando un papel secundario en los procesos de reconciliación.

\section{Conclusiones}

Colombia es un país en donde la guerra y el perdón han coexistido simultáneamente. El perdón ha sido estudiado desde muchas disciplinas, mostrando las aporías existentes en su construcción y la dificultad de su praxis en contextos de reconciliación. Ha sido pensado desde la filosofía, la teología, la ciencia política y la esfera político-jurídica. Desde 
la sociología, aunque algunos (Boltanski, 2000; Boltanski y Thévenot, 1987) se han propuesto devolverle "la realidad sociológica" al perdón, este no ha sido suficientemente estudiado. La sociología cultural, por su parte, ha explicado la importancia de las narrativas colectivas en la construcción de una experiencia traumática con el fin de afectar la acción colectiva y desencadenar la solidaridad de distintas esferas de la sociedad. No obstante, poco ha dicho sobre el perdón.

La presente investigación buscó responder varios interrogantes, entre ellos, qué tanto distan las narrativas dominantes promulgadas por la prensa de las narrativas alternativas de quienes han sufrido la violencia. Encontrar las diferencias entre estos dos discursos de gran importancia en los procesos de reconciliación fue uno de los objetivos de esta investigación. De esta manera, se encontró que la prensa ha difundido narrativas que contrastan con los informes alternativos de quienes han sufrido el conflicto de primera mano.

En los contextos de Justicia Transicional las exigencias jurídicas entran en un juego pragmático con las necesidades políticas. Por ello, figuras como amnistías, indultos y derechos de gracia se hicieron visibles como institucionalización del perdón. En Colombia, esto ha sido común desde la creación de la República. El perdón se ha utilizado como bandera para la legitimación de nuevos gobiernos. Esto se puede observar en los siete perdones fundantes de nuestra historia.

Los periódicos han tenido un papel protagónico en la narración del conflicto colombiano, pero han descuidado las narrativas de reconciliación. ¿Qué pasa con los testimonios de quienes sufrieron la guerra, pero que hoy recuerdan más la superación del trauma que el perdón? Estos discursos de la reconciliación no han sido homogéneos. Cada caso emblemático del conflicto ha mostrado una agenda distinta. Referencias a la memoria como en Trujillo, al reconocimiento de responsabilidad como en Mapiripán, al papel de la Iglesia como en Bojayá, son ejemplo de los distintos enfoques que se le pueden dar a la reconciliación. Estos casos emblemáticos permiten entender la micropolítica de esta acción. 
La disponibilidad de nuevas fuentes ha estimulado el uso de herramientas que organizan grandes colecciones de documentos. Datos cualitativos como los textos no han sido aprovechados en todo su potencial. Mostrar el debate metodológico detrás fue parte importante de esta investigación.

\section{Referencias}

Acosta, María del Rosario (2011). Variaciones sobre el perdón: una sugerencia sobre política y transición a partir de Hegel. Universitas Philosophica, 29(59), 33-50.

Afanador Ulloa, Miguel Angel (1993). Amnistías e indultos: La historia reciente 1948-1992. Bogotá: Escuela Superior de Administración Pública. Universidad del Estado.

Aguilera Peña, Mario (2012, agosto). Refundemos la Nación: perdonemos a delincuentes políticos y comunes. Análisis Político, 25(76), 6-40. Recuperado de http://www.revistas.unal.edu.co/ojs/index.php/anpol/rt/printerFriendly/43493/44782

Alexander, Jeffrey y Dromi, Shai (2011). Trauma Construction and Moral Restriction: The Ambiguity of the Holocaust for Israel. En J. C. Alexander, E. Butler, y R. Eyerman (Eds.). Narrating trauma: on the impact of collective suffering (pp.107-132). Boulder, CO: Paradigm Publishers.

Alexander, Jeffrey y Smith, Philip. (1993). The Discourse of American Civil Society: A New Proposal for Cultural Studies. Theory and Society, (22), 151-207.

Alexander, Jeffrey; Eyerman, Ron; Giesen, Bernhard; Smelser, Neil y Sztompka, Piotr (2004). Cultural Trauma and Collective Identity. Berkeley: University of California Press.

Alexander, Jeffrey; Giesen, Bernhard y Mast, Jason (Eds.). (2006). Social performance: symbolic action, cultural pragmatics, and ritual. Cambridge: Cambridge University Press.

Amat, Yamid (13 de febrero de 2005). Confesión sin efectos penales propone Francisco Santos. El Tiempo. 
Amnistía Internacional (23 de febrero de 1996). Perú. Las leyes de amnistía consolidan la impunidad para las violaciones de derechos humanos. Secretariado Internacional, Londres. Recuperado de http://www.derechos.net/ amnesty/doc/america/peru1.html.

Arendt, Hanna (2005). La condición humana. Barcelona: Paidós.

Bail, Christopher (2013). The cultural environment: measuring culture with big data. Theory and Society, 43(3-4), 465-482.

BBC Mundo (2015). La accidentada reanudación del juicio por genocidio a Ríos Montt. BBC Mundo. Recuperado de http://www.bbc.co.uk/mundo/ noticias/2015/01/150105_guatemala_genocidio_rios_montt_nuevo_juicio_ jcps.

Behar, Olga (1985). Las guerras de la paz. Bogotá: Planeta.

Betancur, Belisario (1984). El camino de la paz. El ansia y la prisa por la paz (Secretaría de Información y Prensa de la Presidencia de Colombia, Vol. 1). Bogotá.

Blei, David (2012). Probabilistic Topic Models. Communications of the ACM, 55(4), 77-84.

Blei, David (2012a). Topic Modeling and Digital Humanities. Journal of Digital Humanities, 2(1).

Blei, David, Ng, Andrew y Jordan, Michael (2003). Latent dirichlet allocation. Journal of Machine Learning Research, 3, 993-1022.

Blei, David, y Lafferty, John (2006). Dynamic topic models. En Proceedings of the $23^{\text {rd }}$ International Conference on Machine Learning (pp. 113-120). New York: ACM.

Blevins, Cameron (1 de abril de 2010). Topic Modeling Martha Ballard's Diary. Disponible en: http://www.cameronblevins.org/posts/topic-modeling-martha-ballards-diary/

Boltanski, Luc (2000). El amor y la Justicia como competencias. Tres ensayos de sociología de la acción. Buenos Aires: Amorrortu Editores.

Boltanski, Luc y Thévenot, Laurent (1987). De la justification. Les économies de la grandeur. París: Gallimard. 
Brogden, Mike (1999). Community policing as cherry pie. En R. I. Mawby (Ed.). Policing across the world. Londres: UCL Press.

Care (Centro de Acercamiento, Reconciliación y Reparación del Municipio de San Carlos). (2007). Recuperado de http://caresancarlos.blogspot.com.co/

Centro Nacional de Memoria Histórica (2008). Trujillo: Una tragedia que no cesa. Bogotá: Editorial Planeta.

Centro Nacional de Memoria Histórica (2010). Bojayá: La Guerra sin Límites. Bogotá: Taurus.

Centro Nacional de Memoria Histórica (2011). San Carlos: Memorias del Éxodo en la Guerra. Bogotá: Taurus. Recuperado de: http://www.centrodememoriahistorica.gov.co/descargas/informes2011/Informe_sancarlos_exodo_en_la_guerra.pdf.

Centro Nacional de Memoria Histórica (2013). ¡Basta ya!: Colombia: memorias de guerra y dignidad (2. ${ }^{\mathrm{a}}$ ed.) Bogotá: Comisión Nacional de Reparación y Reconciliación (Colombia).

Chaparro Castañeda, Natalia (2013). Amnistía e indulto en Colombia: 19652012. Bogotá: Universidad Nacional de Colombia.

Chaparro, Adolfo (2005). La función crítica del "perdón sin soberanía” en procesos de Justicia Transicional. En A. Rettberg (Ed.). Entre el perdón y el paredón: preguntas y dilemas de la justicia transicional (1. ed.) (pp. 181196). Bogotá: Ediciones Uniandes.

Chernick, Marc (2012). Acuerdo posible: solución negociada al conflicto armado colombiano (3. ed.). Bogotá: Ediciones Aurora.

Chirouze Montenegro, Christina (2010). ¿Democratización sin memoria? El caso de Guatemala. Presentado en el IV Encuentro de Latinoamericanistas Españoles: congreso internacional, Sept. 2010, Santiago de Compostela, España (pp. 1389-1404). Recuperado de https://halshs.archives-ouvertes. fr/halshs-00531177/document

Comisión de la Verdad y la Reconciliación de Perú. (2003). Informe final. Lima: CVR. Recuperado de http://www.cverdad.org.pe/ifinal/. 
Comisión para el Esclarecimiento Histórico (1999, junio). Guatemala, memoria del silencio. Managua: Centro de Memoria Histórica, Oficina de Servicios para Proyectos de las Naciones Unidas. Recuperado de http://www.centrodememoriahistorica.gov.co/descargas/guatemala-memoria-silencio/ guatemala-memoria-del-silencio.pdf

Corporación Nuevo Arco Iris (2007). Bojayá: la guerra sin límites. Recuperado de http://www.arcoiris.com.co/2014/02/bojaya-la-guerra-sin-limites/.

Crocker, David (2002). Castigo, perdón y reconciliación. El caso de Sudáfrica. En A. Chaparro (Ed.). Cultura política y perdón (1a. ed.). (pp. 196-217). Bogotá: Centro Editorial Universidad del Rosario.

Cuéllar, Sebastián (2009). Entre la hacienda y la sociedad civil: lógicas culturales de la guerra en Colombia (Tesis de Maestría). Universidad Nacional de Colombia, Departamento de Sociología, Bogotá D. C.

De Sousa Santos, Boaventura (22 de febrero de 2012). Hay otras formas de pensar modernas que no son occidentales y que vienen de pensamientos ancestrales. Rebelión. Recuperado de http://www.rebelion.org/noticia. php?id $=145096$.

De Sousa Santos, Boaventura (2014). Derechos humanos, democracia y desarrollo. Bogotá: Centro de Estudios de Derecho, Justicia y Sociedad (DeJusticia).

Derrida, Jacques (2008). El perdón. En E. Madina; R. Mate; J. Mayorga; M. Rubio; y J. A. Zamora (Eds.). El perdón, virtud política: en torno a Primo Levi (1. ed.). (pp. 113-140). Barcelona: Anthropos Editorial.

Edles, Laura (1998). Symbol and Ritual in the New Spain: The Transition to Democracy after Franco. New York: Cambridge University Press.

Enright, Robert D. y North, Joanna (Eds.). (1998). Exploring forgiveness. Madison, WI: University of Wisconsin Press.

Estructura de la Comunicación de Colombia (03 de marzo de 2006). Historia y principales diarios de Colombia. Recuperado de https://estructuracolombia.wordpress.com/2006/06/03/historia-y-pricipales-diarios-de-colombia/

Fisher, Thomas (2001). Desarrollo hacia afuera y "revoluciones" en Colombia. 1850-1910. En G. Sánchez y M. Aguilera (Eds.). Memoria de un país en guerra. Los mil días 1899-1902. (pp. 33-58) Bogotá: Unijus, Iepri, Planeta. 
Gamboa Tapias, Camila de (Ed.). (2010). El tránsito hacia la paz: de las herramientas nacionales a las locales: estrategias de la transición en cinco países $y$ en tres ciudades colombianas $\left(1 .^{\mathrm{a}}\right.$ ed). Bogotá: Editorial Universidad del Rosario.

Gao, Rui (2011). Revolutionary Trauma and Representation of the War: The Case of China in Mao's Era. En J. C. Alexander, E. Butler y R. Eyerman (Eds.), Narrating trauma: on the impact of collective suffering (pp.53-80). Boulder, CO: Paradigm Publishers.

Garrido, Evelyn (2008). El perdón en procesos de reconciliación: el mecanismo micro-político del aprendizaje para la convivencia. Papel Político, 13(1), 123-167.

Geneva Call (2013). Experiencias de desminado y limpieza de territorios en Colombia. Reflexiones. Recuperado el 10 de septiembre de 2015, de https:// www.genevacall.org/wp-content/uploads/dlm_uploads/2013/12/experencias.pdf

Gibson, James William (1994). Warrior Dreams. Paramilitary Culture in Post-Vietnam America. Chicago: Chicago University Press.

Gobierno de España. (2015). Ley 46/1977, de 15 de octubre, de Amnistía. Agencia Estatal, Boletín Oficial del Estado. Recuperado de http://www. boe.es/buscar/doc.php?id = BOE-A-1977-24937.

Gómez Gallego, Jorge Anibal; Universidad Colegio Mayor de Nuestra Señora del Rosario y Facultad de Jurisprudencia (2010). Informe final de la Comisión de la Verdad sobre los hechos del Palacio de Justicia. Bogotá: Editorial Universidad del Rosario.

Goodman, Tanya. (2006). Performing a "new" nation: the role of the TRC in South Africa. En J. C. Alexander, B. Giesen y J. L. Mast (Eds.). Social performance: symbolic action, cultural pragmatics, and ritual. (pp. 169-192). Cambridge: Cambridge University Press.

Grabe, Vera (2001). Razones de vida. Bogotá: Planeta Colombiana.

Griffiths, Thomas y Steyvers, Mark (2002). A probabilistic approach to semantic representation. En Proceedings of the Annual Conference of the Cognitive Science Society. 
Griffiths, Thomas y Steyvers, Mark (2003). Prediction and semantic association. Advances in Neural information processing systems, 15. 11-18

Griffiths, Thomas y Steyvers, Mark (2004). Finding scientific topics. Proceedings of the National Academy of Science, 101, 5228-5235.

Griffiths, Thomas y Steyvers, Mark (2007). Probabilistic Topic Models. En T. Landauer, S. D. McNamara y W. Kintsch (Eds.). Latent Semantic Analysis: A Road to Meaning. Laurence Erlbaum. Recuperado de: http://psiexp.ss.uci.edu/research/papers/SteyversGriffithsLSABookFormatted.pdf

Hamber, Brandon (2003). Dealing with the Past: Rights and Reasons: Challenges for Truth Recovery in South Africa and Northern Ireland. Fordham International Law Journal, 26.1074-1094

Heins, Volker y Langenohl, Andreas (2011). A Fire That Doesn't Burn? The Allied Bombing of Germany and the Cultural Politics of Trauma. En: J. C. Alexander, E. Butler, y R. Eyerman (Eds.). Narrating trauma: on the impact of collective suffering (pp.3-26). Boulder, CO: Paradigm Publishers.

Hilb, Claudia (2012). ¿Cómo fundar una comunidad después del crimen? Una reflexión sobre el carácter político del perdón y la reconciliación a la luz de los juicios a las Juntas en Argentina y de la Comisión de la Verdad y la Reconciliación en Sudáfrica. En L. Quintana y Vargas J. (Eds.). Hannah Arendt. Política, violencia, memoria. Bogotá: Ediciones Uniandes.

Jankélévitch, Vladimir (1967). El perdón. Barcelona: Seix-Barral.

Jimeno, Myriam, Castillo, Ángela y Varela, Daniel. "Experiencias de violencia: etnografía y recomposición social en Colombia”. En: Sociedade e Cultura, Universidade Federal de Goiás, Goiânia. No. 2, Vol. 14, jul.- dic., 2011, págs $275-285$.

Jimeno, Myriam; Castillo, Ángela y Varela, Daniel (2009). A los siete años de la masacre del Naya: la perspectiva de las víctimas. Bogotá: Universidad Nacional de Colombia, Centro de Estudios Sociales CES.

Lanski, Wendy (11 de septiembre de 2015). La víctima del 11 de septiembre que decidió no perdonar. Reconciliación Colombia.

Lefranc, Sandrine (2005). Políticas del perdón. Bogotá: Grupo Editorial Norma. 
López de la Roche, Fabio (2002). Una opinión pública sólida para la reconciliación y la reconstrucción nacional. En A. Chaparro Amaya (Ed.), Cultura política y perdón (1. ${ }^{a}$ ed, pp.227-234). Bogotá: Centro Editorial Universidad del Rosario.

Marvin, Carolyn y Ingle, David W. (1999). Blood sacrifice and the nation: totem rituals and the American flag. Cambridge: Cambridge University Press.

Melo, Jorge Orlando (2002). Perdón y procesos de reconciliación. En A. Chaparro Amaya (Ed.). (2002). Cultura política y perdón (1. ${ }^{a}$ ed.). Bogotá: Centro Editorial Universidad del Rosario.

Ministerio del Posconflicto, Derechos Humanos y Seguridad. (2015). Víctimas de minas antipersonal. Recuperado de http://www.accioncontraminas. gov.co/estadisticas/Paginas/victimas-minas-antipersonal.aspx.

Minow, Martha (1998). Between Vengeance and Forgiveness. Boston: Beacon Press Books.

Minow, Martha; Crocker, David; Mani, Rama y Saffon, María Paula (2011). Justicia Transicional. Bogotá: Siglo del Hombre Editores, Universidad de los Andes, Universidad Javeriana, Instituto Pensar.

Molano, Alfredo (1980). Amnistía y violencia. Bogotá. Centro de Investigación y Educación Popular- Cinep.

Navarro Wolff, Antonio y Iragorri, Juan Carlos (2004). Mi guerra es la paz: Navarro se confiesa con Juan Carlos Iragorri. Bogotá: Editorial Planeta.

Nelson, Robert (s. f.). “Mining the Dispatch.” University of Richmond, 2011. Tomado de: http://dsl.richmond.edu/dispatch/ el 12 de septiembre de 2015.

Premio Nacional de Paz (2011). Ganadores Premio Nacional de Paz 2011. Centro Nacional de Noticias de la Educación. Ministerio de Educación. Recuperado de http://www.mineducacion.gov.co/cvn/1665/w3-article-290486. html

Prodepaz (2010, agosto). Segundo laboratorio de paz para Colombia: Región Oriente Antioqueño. Bogotá: Corporación Programa Desarrollo para la Paz. Recuperado de http://www.programadesarrolloparalapaz.org/phocadownload/ejecucionproyect/InformeLaboratoriodePaz.pdf 
Ramírez, Socorro y Restrepo, Luis Alberto (1988). Actores en conflicto por la paz: el proceso de paz durante el gobierno de Belisario Betancur (19821986). México: Siglo Veintiuno, Cinep.

Revista Semana (7 de junio de 2013). Proyecto Víctimas.

Ricoeur, Paul (2003). La memoria, la historia, el olvido. Madrid: Editorial Trotta.

Rivas, Pedro, y Marrodán, Javier (2007). Sudáfrica. El perdón como motor de la historia. Nuestro Tiempo. Revista Cultural y de Cuestiones Actuales de La Universidad de Navarra, 678. Recuperado de http://www.unav.es/nuestrotiempo/es/temas/sudafrica-el-perdon-como-motor-de-la-historia.

Rodríguez Maldonado, Tatiana. (2015). Imagen y discurso: construcción de sentido en las portadas de las revistas Semana y Cambio 1998-2004. Disponible en: http://www.banrepcultural.org/blaavirtual/todaslasartes/monografia/mono2a.htm

Roht-Arriaza, Naomi (2005). The Pinochet Effect. Transnational Justice in the Age of Human Rights. Pensilvania: University of Pennsylvania Press.

Sánchez G., Gonzalo (1985). Ensayos de historia social y política del siglo XX. Bogotá: Áncora Editores.

Schuster, Sven (2009). Las políticas de la historia en Colombia: el primer gobierno del Frente Nacional y el "problema” de la Violencia (1958-1962). Iberoamericana, $\operatorname{IX(36),~9-26.~}$

Theidon, Kimberly (2004). Entre prójimos. El conflicto armado interno y la política de la reconciliación en el Perú. Estudios de la Sociedad Rural, 24.

Unidad para la Atención y Reparación Integral a las Víctimas (2017). Reportes. Red Nacional de Información. Información Al Servicio de Las Víctimas. Recuperado de http://rni.unidadvictimas.gov.co/v-reportes.

Uprimny Yepes, Rodrigo (2006). Las enseñanzas del análisis comparado: procesos transicionales, formas de justicia transicional y el caso colombiano. En Rodrigo Uprimny et al. ¿Justicia transicional sin transición?. (pp. 17-44) Bogotá: Centro de Estudios de Derecho, Justicia y Sociedad (DeJusticia). 
Uprimny Yepes, Rodrigo y Saffon, María Paula (2006). Justicia transicional y Justicia restaurativa: tensiones y complementariedades. En iJusticia transicional sin transición?. Verdad, justicia y reparación para Colombia. Bogotá: Centro de Estudios de Derecho, Justicia y Sociedad (DeJusticia).

Uribe, María Teresa (2003). Las guerras civiles y la negociación política: Colombia, primera mitad del siglo XIX. Revista de Estudios Sociales, (16), 29-41.

Valcárcel, Amelia (2010). La memoria y el perdón. Barcelona: Herder.

Valencia Agudelo, León y Velásquez C., Fabio, (Eds.). (2009). Municipio y violencia paramilitar en Colombia 1984-2008. En Las otras caras del poder: territorio, conflicto y gestión pública en municipios colombianos (pp.141178). Bogotá: GTZ, Foro Nacional por Colombia.

Vargas Velásquez, Alejo (2002). Reflexiones acerca del perdón y la amnistía en conflictos internos armados. En A. Chaparro Amaya (Ed.). Cultura política y perdón.(pp. 218-226.) Bogotá: Centro Editorial Universidad del Rosario.

Villar Borda, Luis (1982). Oposición, insurgencia y amnistía. Bogotá: Dintel.

Wilson, Richard (2002). Challenging Restorative Justice. Human Rights Dialogue, 7. Recuperado de www.cceia.org/viewMedia.php/prmID/246.

\section{Prensa}

El Espectador (2008-2015). 451 artículos tomados de: http://www.elespectador.com

El Tiempo (2008-2015). 392 artículos tomados de: http://www.eltiempo.com

Semana (2008-2015). 564 artículos tomados de: http://www.semana.com

El Espectador (diciembre de 2014). Bojayá, El perdón que ofrecen las FARC.” El Espectador. Recuperado de https://www.elespectador.com/noticias/paz/ bojaya-el-perdon-ofrecen-farc-articulo-533985

Gallón, Gustavo (2011). El paramilitarismo inocente. El Espectador. Recuperado de: https://www.elespectador.com/opinion/el-paramilitarismo-inocente-columna- 233040 
Álvarez, Víctor Andrés (22 de diciembre de 2014). Mi familia merece que las FARC le pidan perdón: Aníbal Gaviria. El Tiempo Recuperado de: http:// www.eltiempo.com/archivo/documento/CMS-15011740

La Voz del Pueblo (1849). La Voz del Pueblo. Recuperado de: http://www.banrepcultural.org/sites/default/files/revista/brblaa_619262_001.pdf

Semana (6 de marzo de 1995). Testimonio atroz. Semana. Recuperado de: https://www.semana.com/nacion/articulo/testimonio-atroz/24924-3

Verdad Abierta (17 de octubre de 2008). Diócesis de Quibdó, ganadora de Premio Nacional de Paz 2005 (Semana). Recuperado de: http://www.verdadabierta.com/victimas-seccion/los-resistentes/444-diocesis-de-quibdoganadora-de-premio-nacional-de-paz-2005-semana

Verdad Abierta (15 de octubre de 2008). Bloque Elmer Cárdenas de Urabá. Verdad Abierta. Recuperado de: https://verdadabierta.com/bloque-elmercardenas-de-uraba-/

\section{Relatos y testimonios}

Centro Nacional de Memoria Histórica. (2004). Algunos indicadores sobre la situación de Derechos Humanos en la región del Urabá Antioqueño.

Centro Nacional para la Justicia Transicional. (Agosto 2009). Recordar en conflicto: iniciativas no oficiales de memoria en Colombia. Recordar y Reparar. Unión Europea.

Centro Nacional de Memoria Histórica. Testimonios (2009). San Carlos, Antioquia.

Centro Nacional de Memoria Histórica.Testimonio Hombre, Fundación Tesodi, febrero 23 de 2009. San Carlos, Antioquia.

Centro Nacional de Memoria Histórica. Testimonios (2011). Bojayá, Chocó.

Centro Nacional de Memoria Histórica. (2012). Mapiripán sin conmemoración de 15 años. 15 julio 2012.

Centro Nacional de Memoria Histórica. Defensoría del Pueblo. (2013). Narrativas Visibles, Hasta Cuándo. 
Corporación Nuevo Arco Iris. (2007). Programa Poblaciones Afectadas por el Conflicto. La memoria desde las víctimas II. Chocó: por los hijos y la tierra despojada (Curvaradó, 1996-2002). Bogotá.

Corte Interamericana de Derechos Humanos. 6 de octubre de 1999. Caso de la masacre de Mapiripán. Colombia. Sentencia de 15 septiembre de 2005.

Corte Interamericana de Derechos Humanos de 3 de mayo de 2008. Caso de la masacre de Mapiripán.

Defensoría del Pueblo (2014). Crisis Humanitaria en Chocó. Diagnóstico, valoración y acciones de la Defensoría del Pueblo. Defensoría del Pueblo. Bogotá.

Habitantes de Trujillo (Valle). (2003). Tiberio Vive Hoy. Testimonios de la vida de un mártir, Tiberio Fernández Mafla.

Instituto Colombiano de Bienestar Familiar y Organización Internacional para las Migraciones. (2012). Memorias del Proceso de Fortalecimiento Social para la Reconciliación en el Municipio de Trujillo, Valle del Cauca. 2008-2011.

Instituto Popular de Capacitación. (2012). Conflicto y formas expresivas de la violencia en contextos situados: aproximación a cuatro territorios de Antioquia. Informe de Derechos Humanos.

Observatorio del Programa Presidencial de DH y DIH Vicepresidencia de la República. (2010). Diagnóstico de la situación de los municipios habitados por las comunidades afrocolombianas priorizadas por la Honorable Corte Constitucional en el Departamento de Chocó.

Unidad para la Atención y Reparación Integral a las Víctimas. (2012). Chocó: Informe Departamental de Hechos Victimizantes a 2012. Presidencia de la República.

\section{Videos}

Contravía (2012). Trujillo- Memoria de una masacre. Recuperado de: https:// www.youtube.com/watch? $\mathrm{v}=6 \mathrm{SAJ} 8 \mathrm{MsmGoI}$.

Contravía (2008). Trujillo: Una tragedia que no cesa. (Parte1/3). Recuperado de: https://www.youtube.com/watch?v = YJusq-1k5CY

Centro Nacional de Memoria Histórica (2010). Precio de la Tierra. Bojayá. Bogotá. 
Comisión Nacional de Reparación y Reconciliación (s.f.) Capítulo 6, Nunca Más: Trujillo, una gota de esperanza en un mar de impunidad. Recuperado de: https://www.youtube.com/watch? $\mathrm{v}=3 \mathrm{wqKL}-\mathrm{cUJSM}$

Corporación Colectivo de Abogados José Alvear Restrepo. (2012). Hagamos memoria. Producido por Morris Producciones. Canal Capital. Colombia.

Premio Nacional de Paz: 2005. (2008). El Tiempo. Recuperado de: https:// www.youtube.com/watch?v = YrwR_pCk-Zg

Programa Andino para la Democracia y los Derechos Humanos de la Unión Europea (20 de Septiembre de 2010). Contravía: Masacre de Mapiripán (Parte I). Recuperado de: https://www.youtube.com/watch?v = SKo4gSwlYlU 